\title{
A long hypoxia-inducible factor 3 isoform 2 is a transcription activator that regulates erythropoietin
}

\author{
Jussi-Pekka Tolonen ${ }^{1,2} \cdot$ Minna Heikkilä ${ }^{1,2} \cdot$ Marjo Malinen $^{3} \cdot$ Hang-Mao Lee $^{2} \cdot$ Jorma J. Palvimo $^{4} \cdot$ Gong-Hong Wei ${ }^{2}$. \\ Johanna Myllyharju ${ }^{1,2}$ (1)
}

Received: 16 April 2019 / Revised: 12 November 2019 / Accepted: 15 November 2019 / Published online: 25 November 2019

(c) The Author(s) 2019

\begin{abstract}
Hypoxia-inducible factor (HIF), an $\alpha \beta$ dimer, is the master regulator of oxygen homeostasis with hundreds of hypoxiainducible target genes. Three HIF isoforms differing in the oxygen-sensitive $\alpha$ subunit exist in vertebrates. While HIF-1 and HIF-2 are known transcription activators, HIF-3 has been considered a negative regulator of the hypoxia response pathway. However, the human HIF3A mRNA is subject to complex alternative splicing. It was recently shown that the long HIF-3 $\alpha$ variants can form $\alpha \beta$ dimers that possess transactivation capacity. Here, we show that overexpression of the long HIF-3 $\alpha 2$ variant induces the expression of a subset of genes, including the erythropoietin $(E P O)$ gene, while simultaneous downregulation of all HIF-3 $\alpha$ variants by siRNA targeting a shared HIF3A region leads to downregulation of $E P O$ and additional genes. EPO mRNA and protein levels correlated with HIF3A silencing and HIF-3 $\alpha 2$ overexpression. Chromatin immunoprecipitation analyses showed that HIF-3 32 binding associated with canonical hypoxia response elements in the promoter regions of $E P O$. Luciferase reporter assays showed that the identified HIF-3 $\alpha 2$ chromatin-binding regions were sufficient to promote transcription by all three HIF- $\alpha$ isoforms. Based on these data, HIF-3 2 2 is a transcription activator that directly regulates $E P O$ expression.
\end{abstract}

Keywords Hypoxia response · Hypoxia-inducible factor 3 isoform · Transcription activator · Erythropoietin · Chromatin immunoprecipitation · Hypoxia response element

\section{Introduction}

Oxygen-dependent organisms have developed elaborate means to maintain appropriate intracellular oxygen levels for the physicochemical reactions that occur within cells. The master regulators of oxygen homeostasis are the heterodimeric hypoxia-inducible factors (HIFs), present in some form in all metazoan species studied so far $[1,2]$. When intracellular oxygen tension decreases below a typical

Johanna Myllyharju

johanna.myllyharju@oulu.fi

1 Oulu Center for Cell-Matrix Research, University of Oulu, PO Box 5400, 90014 Oulu, Finland

2 Biocenter Oulu and Faculty of Biochemistry and Molecular Medicine, University of Oulu, 90014 Oulu, Finland

3 Department of Environmental and Biological Sciences, University of Eastern Finland, 80100 Joensuu, Finland

4 Institute of Biomedicine, University of Eastern Finland, 70211 Kuopio, Finland concentration, the HIFs initiate and control graded mechanisms to reduce oxygen consumption and to increase oxygen availability via oxygen-dependent regulation of a genetic hypoxia response pathway $[3,4]$.

Three HIF- $\alpha$ subunit isoforms (HIF- $1 \alpha$, HIF-2, and HIF-3 $\alpha$ ) have been identified in vertebrates, encoded by three separate genes (HIFIA, EPAS1, and HIF3A), with $H I F 3 A$ mRNA being subject to diverse alternative splicing [5-10]. HIF-1 $\alpha$, HIF- $2 \alpha$, and some HIF-3 $\alpha$ variants contain basic helix-loop-helix-PAS domains, which facilitate heterodimerization with the HIF- $\beta$ subunit, encoded by the ARNT gene, and binding to DNA [11]. Towards their C-terminus, the HIF- $\alpha$ protein also possess an oxygen-dependent degradation domain (ODDD), which accounts for their oxygendependent regulation. HIF- $1 \alpha$ and HIF- $2 \alpha$ contain two transactivation domains (NTAD and CTAD), whereas the long HIF3A splicing variants contain only the NTAD [12].

The HIFs bind to specific hypoxia-responsive elements (HREs) with a canonical core sequence (5'-RCGTG-3') [13]. According to genome-wide chromatin immunoprecipitation 
sequencing (ChIP-seq) studies, approximately $40 \%$ and $20 \%$ of HREs for HIF-1 and HIF-2, respectively, reside in promoter regions within a $2.5-\mathrm{kb}$ range from transcription initiation sites (TSS) [14]. HIF-1 appears to bind HREs in promoter regions, while HIF-2 binds more distant regions such as enhancers [15]. Most importantly, however, HIF-1 and HIF-2 do not compete for the same binding sites [15]. The HIF-3 $\alpha \beta$ dimer has been shown to recognize the canonical HRE [16], but the genome-wide binding of the human HIF-3 and its consequences have not been characterized.

Erythropoietin (EPO), the main regulator of red blood cell production, is a classic hypoxia-inducible gene mainly targeted by HIF-2 [17]. It is produced in the liver during early development and later in the kidney [18]. A 256-bp liver inducibility element (LIE) has been identified immediately $3^{\prime}$ to the gene in Hep3B cells, whereas a negative regulatory element (NRE) lies 4-6 kb upstream of the gene [19-22]. A kidney inducibility element (KIE) lies even farther upstream (9.5 to $14 \mathrm{~kb}$ ), regulating $E P O$ transcription in peritubular interstitial fibroblasts $[17,21]$. The single HRE found in the LIE is crucial for maximal EPO expression and is probably bound only by HIF-2 in accordance with HIF-2 binding to enhancers [15, 17, 22-24]. Although some candidates for the kidney-specific HRE have been identified in vitro and in vivo, no definite consensus exists [24-26]. Of note, HIFIA knockdown does not suppress EPO expression in the three cell lines studied so far, namely, Hep3B, Kelly, and cortical astrocytes [23, 27].

Studies of the HIF pathway have thus far focused mainly on HIF-1 and HIF-2, leaving HIF-3 a relatively unknown regulator of the hypoxia response. Previous experiments conducted in mice suggested that a short splice variant of Hif $3 a$, the inhibitory PAS domain containing protein (IPAS), acts as a dominant negative inhibitor of the hypoxia response by forming inactive complexes with HIF- $1 \alpha$ and HIF-2 $\alpha[5-7,9,28]$. The short human HIF3A splice variant, HIF-3 $\alpha 4$, inhibits the hypoxia response in a similar dominant negative manner [10, 12, 29]. However, more recent studies have suggested that each HIF-3 $\alpha$ variant mayperform manifestly different roles and that the long HIF-3 variants possess transactivation activity $[9,12,30,31]$. Furthermore, we have previously shown that simultaneous in vitro knockdown of all human HIF3A splice variants results in the downregulation of several hypoxia-inducible genes including $E P O$ [12]. Similar to other transcription factors with dominant negative and transactivating splice variants, such as the IKAROS family zinc finger 1 [32], HIF-3 may thus be a hypoxiainducible transcription factor with a dual role.

To test our hypothesis that human HIF-3 can induce the transcription of certain hypoxia-inducible genes, we carried out a cDNA microarray screen of hypoxia-dependent HIF-3 target genes in Hep3B cells. Under hypoxia, an overexpression of the long HIF-3 32 splice variant resulted in over twofold upregulation of eight genes, including EPO. HIF-3 clearly contributed to EPO signaling as overexpression of HIF-3 22 in two cell lines capable of endogenous EPO production, namely, Hep3B and the SK-N-AS neuroblastoma cell line, and siRNA knockdown of all HIF3A variants in the SK-N-AS cells resulted in significant changes in EPO mRNA and protein levels that are in line with the hypothesis that HIF-3 is a transcription activator. Our ChIP data suggest that HIF- 3 binds its target genes via the canonical HRE. The HIF-3-binding regions are sufficient to drive the transcription of luciferase reporter genes when co-transfected with one of the HIF- $\alpha$ isoforms and HIF- $\beta$. These data indicate that at least one of the long HIF-3 $\alpha$ variants is a transcription activator involved in erythropoietin signaling by binding directly on $E P O$ and inducing its transcription.

\section{Materials and methods}

\section{Cell culture}

Hep3B hepatoma cells were cultured in Earle's minimum essential medium (Sigma, USA), ChoK1 cells were cultured in Dulbecco's minimum essential medium (Biochrom AG, Germany) with $0.375 \%$ sodium bicarbonate (Sigma) and SK-N-AS neuroblastoma cells were cultured in RPMI 1640 (Gibco, USA). The culture media for Hep3B and ChoK1 cells were supplemented with $0.1 \mathrm{mM}$ non-essential amino acids (Sigma), $1 \mathrm{mM}$ sodium puryvate (Sigma), 10\% fetal bovine serum (HyClone, USA), $2 \mathrm{mM}_{\mathrm{L}}$-glutamine (Sigma), and $100 \mathrm{U} / \mathrm{ml}$ penicillin with $0.1 \mathrm{mg} / \mathrm{ml}$ streptomycin (Gibco), while the SK-N-AS culture medium was supplemented with $10 \%$ fetal bovine serum (Sigma) and $100 \mathrm{U} /$ $\mathrm{ml}$ penicillin with $0.1 \mathrm{mg} / \mathrm{ml}$ streptomycin (Gibco). Cell culture under hypoxic conditions $\left(1 \% \mathrm{O}_{2}, 5 \% \mathrm{CO}_{2}\right.$, and $94 \%$ $\mathrm{N}_{2}$ ) was performed in the Invivo ${ }_{2}$ Hypoxia Workstation 400 (Ruskinn Technologies, UK) for cDNA microarray studies, and the Sci-Tive-N (Baker Ruskinn, UK) hypoxia station for all other experiments. As the Hep3B cells express $E P O$ and other endogenous human hypoxia-inducible genes, they were chosen for the ChIP, cDNA microarray and functional experiments. The ChoK 1 cell line was used as a host for the luciferase reporter assay due to its high transfection rate. The SK-N-AS cells that also express $E P O$ were used to confirm results obtained in Hep3B cells.

\section{Expression plasmids and preparation of the HIF-3a antibody}

The following expression plasmids described previously were used in this study: pcDNA3.1/Zeo(-)-V5-HisA, pEGFP-N1, full-length untagged human HIF- $1 \alpha$, HIF- $2 \alpha$, 
and HIF- $\beta$, and untagged as well as C-terminal V5-tagged human HIF-3 $\alpha 2$ [10, 12].

To generate luciferase reporter constructs for HIF- $3 \alpha 2$ binding sites identified by ChIP-seq in $E P O$, angiopoietinlike-4 (ANGPTL4) and Histone Cluster 1 H2B Family Member $\mathrm{K}(H I S T 1 H 2 B K)$ genes, the DNA for the binding sites was amplified and cloned into the pGL4.75 vector (Promega, USA). To study the dependency of HIF- $1 \alpha$ and HIF- $3 \alpha 2$ binding on the canonical HRE sequences ( $5^{\prime}$-RCGTG-3'), all such sites found within the HIF- $3 \alpha 2$ HIST1H2BK binding site on the forward and reverse strands were mutated to 5'-ATTTA-3' (denoted mutHIST1H2BK) using the QuickChangeXL II site-directed mutagenesis kit (Stratagene, USA) according to manufacturer's instructions. Mutagenesis primers are listed in Table 1.

To produce the HIF- $3 \alpha 2$ antibody used in the qPCRbased ChIP studies, High Five insect cells (Thermo Fisher Scientific, USA) were infected with an HIF-3 $\alpha 2$ expression plasmid containing the FLAG-His tag. The denatured HIF- $3 \alpha 2$ protein was then purified by QIAexpress metal chelate chromatography (QIAGEN, Germany) according to manufacturer's instructions. Polyclonal antisera were produced at Innovagen $\mathrm{Ab}$ (Lund, Sweden) by immunizing rabbits with the denaturated recombinant HIF- $3 \alpha 2$ protein. The antisera were tested to exclude cross-reactivity with HIF- $1 \alpha$ and HIF- $2 \alpha$, after which the HIF-3 $\alpha 2$ antibody was purified using HiTrap Protein G HP columns (Amersham, USA) according to manufacturer's instructions.

\section{CDNA microarray and qPCR analysis}

For overexpression, $300000 \mathrm{Hep3B}$ cells were co-transfected once with either $1000 \mathrm{ng}$ of pcDNA3.1/Zeo(-) or $1000 \mathrm{ng}$ of HIF-3 $\alpha 2$ plasmid with $1000 \mathrm{ng}$ of HIF- $\beta$ plasmid using FuGENE HD (Promega) and cultured for $24 \mathrm{~h}$ in normoxia and then $24 \mathrm{~h}$ in $1 \%$ hypoxia. For RNA interference, 300,000 cells were transfected twice with HIF3A siRNA (siGENOME, USA, MQ-010068-03-0005) targeting all HIF3A splice variants using siPORT NeoFX (Ambion, USA) at a 24-h interval and cultured under hypoxia for $24 \mathrm{~h}$ after the second transfection. All samples were prepared in triplicate and pooled for cDNA microarray analysis. RNA was isolated by E.Z.N.A Total RNA kit I (Promega). cDNA was prepared using the iScript cDNA Synthesis Kit (BioRad, USA). The microarray was conducted using two Affymetrix Human Genome U133 Plus 2.0 Array chips with an Affymetrix Gene Chip Scanner 3000 7G (Thermo Fisher Scientific, USA) in Biocenter Oulu DNA Analysis Core, and the data were analyzed using the Chipster software (https ://chipster.csc.fi/, version 3.12) [33]. Functional pathway analyses were carried out by Chipster using hypergeometric test for Gene Ontology (GO) with default settings. The microarray data have been deposited in the Gene Expression Omnibus database with accession number GSE128847.

The results of the microarray analysis were verified by quantitative real-time PCR (qPCR) with gene-specific primers (Table 1) and SsoFast EvaGreen Supermix (Bio-Rad) with a CFX96 Touch real-time PCR detection system (BioRad). TATA box-binding protein (TBP), or $\beta$-actin $(A C T B)$ and hypoxanthine phosphoribosyltransferase 1 (HPRT1) mRNA were used as reference genes for Hep3B and SK-NAS cells, respectively.

\section{Chromatin immunoprecipitation (ChIP) followed by high-throughput sequencing (ChIP-seq)}

ChIP experiments were performed as described previously [34]. Briefly, $1.6 \times 10^{6} \mathrm{Hep} 3 \mathrm{~B}$ cells were co-transfected with $6000 \mathrm{ng}$ of HIF-3 $\alpha 2$-V5 and $4000 \mathrm{ng}$ of HIF- $\beta$ plasmids, cultured under normoxic conditions for $24 \mathrm{~h}$ and continued $24 \mathrm{~h}$ at $1 \%$ oxygen prior to ChIP. For the qPCR based ChIP studies, the control samples were co-transfected with $10,000 \mathrm{ng}$ of pcDNA3.1-V5-HisA. Cells were crosslinked with $1 \%(\mathrm{v} / \mathrm{v})$ formaldehyde and harvested for sonication to an average fragment size of $200-400 \mathrm{bp}$ using Bioruptor UCD-300-TO (Diagenode, USA). The chromatin was immunoprecipitated for ChIP-seq with V5-tag antibody (R960-25, Invitrogen, USA) and for qPCR-based ChIP assays with the HIF3A antibody described above, and normal rabbit IgG (sc-2027, Santa Cruz Biotechnology, USA). ChIP-seq samples were processed according to Illumina's instructions and DNA libraries were sequenced using Illumina HiSeq System (Illumina, USA) in the EMBL Gene Core Facility (Heidelberg, Germany). The qPCR-based ChIP results were normalized with respect to input. Fold changes were calculated using the formula $2^{-(\Delta \mathrm{Ct})}$, where $\Delta \mathrm{Ct}$ is $\mathrm{Ct}_{\text {(immunoprecipitated DNA) }}-\mathrm{Ct}_{\text {(input) }}$ and $\mathrm{Ct}$ is the cycle at which the threshold line is crossed. The primers are listed in Table 1. The ChIP-seq data have been deposited in the Gene Expression Omnibus database with accession number GSE129491.

\section{HIF-3a2 peak calling and Integrative Genomics Viewer visualization}

The original Fastq files were trimmed by ngsShoRT with the option "lqr_5adpt_tera". Reads were aligned to hg19 human genome by Bowtie2. For the functional analyses, peaks were called by Homer with default parameters. De novo motifs were discovered by Homer. To visualize HIF-3 $\alpha 2$ binding at certain target genes, peaks were called using the MACS algorithm with input as control. The bedGraph format from MACS was converted to bigwig using the UCSC pre-compiled utilities bedGraphToBigWig provided with chromosome sizes. Finally, the bigWigToWig utility was 
Table 1 Sequences of the primers used in cloning, mutagenesis, RNA interference, qPCR analyses, ChIP studies, and luciferase reporter experiments

\begin{tabular}{|c|c|c|c|}
\hline Gene & Use & Primer ID & Sequence $\left(5^{\prime} \rightarrow 3^{\prime}\right)$ \\
\hline \multirow[t]{2}{*}{$A C T B$} & qPCR & b-ActinFw & TGTGGCATCCACGAAACTAC \\
\hline & qPCR & b-ActinRv & TCATACTCCTGCTTGCTGATCC \\
\hline \multirow[t]{4}{*}{ ANGPTLA } & ChIP-qPCR & ANGPTL4_cQ_F & AAGTGTATGAGTGGCAGCCT \\
\hline & ChIP-qPCR & ANGPTL4_cQ_R & AACTTGCACCGATCTCCTCT \\
\hline & Cloning & ANGPTL4_B_F & GCGAGATCTCACGGTTCGTAGAGGAAGGC \\
\hline & Cloning & ANGPTL4_B_R & GCGAAGCTTCCCACTCCTGTCCATACCCT \\
\hline \multirow[t]{2}{*}{ EIF5A } & ChIP-qPCR & EIF5A_cQ_F & TGGAGATGGGTAGGGTGTGT \\
\hline & ChIP-qPCR & EIF5A_cQ_R & GACCAACCAAGCAGCCCTAT \\
\hline \multirow[t]{2}{*}{ EPAS1 } & qPCR & Q_HIF2a_F & CCCAGATCCACCATTACAT \\
\hline & qPCR & Q_HIF2a_R & ACTCCAGCTGTCGCTTCA \\
\hline \multirow[t]{2}{*}{$E P O$} & qPCR & EPO_RT_F & CTCCGAACAATCACTGCT \\
\hline & qPCR & EPO_RT_R & GGTCATCTGTCCCCTGTCCT \\
\hline (Control) & ChIP-qPCR & EPO_ctrl_cQ_F & GGAAGGCAATTTTGTGTGCG \\
\hline \multirow[t]{5}{*}{ (Control) } & ChIP-qPCR & EPO_ctrl_cQ_R & CCAAGCACCAGAAACTCACC \\
\hline & ChIP-qPCR & EPO_cQ_F & CCAGTGGAGAGGAAGCTGAT \\
\hline & ChIP-qPCR & EPO_cQ_R & СТTCCTTCATCCCCACGTCT \\
\hline & Cloning & EPO-1_F & GCGGAGCTCGGATTGTGGGAAGGGAGACC \\
\hline & Cloning & EPO-1_R & GCGCTCGAGATAGCCGGGGCGCTAAATC \\
\hline \multirow[t]{2}{*}{ EPOR } & ChIP-qPCR & EPOR_cQ_F & TAGGCAGCGAACACCAGAAG \\
\hline & ChIP-qPCR & EPOR_cQ_R & TCACACACACACACAAGGCT \\
\hline \multirow[t]{2}{*}{ HIF1A } & qPCR & Q_HIF1a_F & CTAGCTTTGCAGAATGCTCAG \\
\hline & qPCR & Q_HIF1a_R & GTAGTAGCTGCATGATCGTCTG \\
\hline \multirow[t]{7}{*}{$H I F 3 A$} & RNAi & siHIF3A_a & UAACAGGGCAGUAUCGCUU \\
\hline & RNAi & siHIF3A_b & CGACAGGAUUGCAGAAGUG \\
\hline & RNAi & siHIF3A_c & GCAAGAGCAUCCACACCUU \\
\hline & RNAi & siHIF3A_d & GAACUGCUCUGGACAUAUG \\
\hline & RNAi & siHIF3A_e & SR312024B, sequence not available \\
\hline & qPCR & Q_HIF3a_all_F & CCCCACGGAGCGGTGCTTCT \\
\hline & qPCR & Q_HIF3a_all_R & AGTCTGCGCAGGTGGCTTGT \\
\hline \multirow[t]{14}{*}{$H I S T 1 H 2 B K$} & qPCR & HIST1H2BK_Q_F & TGCTGCTCGTCTCAGGCTCGT \\
\hline & qPCR & HIST1H2BK_Q_R & CTCTCCTTGCGGCTGCGCTT \\
\hline & ChIP-qPCR & HIST1H2BK_cQ_F & GGGCCCCTAAGCTTTCAACA \\
\hline & ChIP-qPCR & HIST1H2BK_cQ_R & GGCTCTTCTGGCCTTGGAAA \\
\hline & Cloning & HIST1H2BK_R & GCGGAGCTCCGGCGTCGAGTTAATCTTGT \\
\hline & Cloning & HIST1H2BK_R & GCGCTCGAGTCCGGTTTTCAGTCTGGTCC \\
\hline & Mutagenesis & HIST1H2BK_HRE1_F & AAGACGGTCACCGCCATGGTAAATGTCTACGCGCTCAAGCGCC \\
\hline & Mutagenesis & HIST1H2BK_HRE1_R & GGCGCTTGAGCGCGTAGACATTTACCATGGCGGTGACCGTCTT \\
\hline & Mutagenesis & HIST1H2BK_HRE2_F & GCCGTGACCTACACGGAGTAAATCAAGCGCAAGACGGTCAC \\
\hline & Mutagenesis & HIST1H2BK_HRE2_R & GTGACCGTCTTGCGCTTGATTTACTCCGTGTAGGTCACGGC \\
\hline & Mutagenesis & HIST1H2BK_HRE3_F & TGTTGAAGGTGTTCCTGGAGATAAATATCCGGGACGCCGTGACCTACAC \\
\hline & Mutagenesis & HIST1H2BK_HRE3_R & GTGTAGGTCACGGCGTCCCGGATATTTATCTCCAGGAACACCTTCAACA \\
\hline & Mutagenesis & HIST1H2BK_HRE4_F & TGCTCGCCGCGGCGTAAATAAGCGCATTTCTGGCCTCATCTATGAG \\
\hline & Mutagenesis & HIST1H2BK_HRE4_R & CTCATAGATGAGGCCAGAAATGCGCTTATTTACGCCGCGGCGAGCA \\
\hline \multirow[t]{2}{*}{ HPRT1 } & qPCR & hHprt_F & CCTGGCGTCGTGATTAGTGAT \\
\hline & qPCR & hHprt_R & AGACGTTCAGTCCTGTCCATAA \\
\hline \multirow[t]{2}{*}{ PMB6 } & qPCR & hPMB6qfor & AGCGACACCACAAAGAGTTCA \\
\hline & qPCR & hPMB6qrev & GCTGATGCTCCTGTAAGACTTGA \\
\hline \multirow[t]{2}{*}{ PSMD5 } & ChIP-qPCR & PSMD5_cQ_F & AATCTTGATCCTGGGCCAGC \\
\hline & ChIP-qPCR & PSMD5_cQ_R & GCGCACGTCCCTATTACTCA \\
\hline
\end{tabular}


Table 1 (continued)

\begin{tabular}{llll}
\hline Gene & Use & Primer ID & Sequence $\left(5^{\prime} \rightarrow 3^{\prime}\right)$ \\
\hline PTX3 & qPCR & hPTXqfor & CATCTCCTTGCGATTCTGTTTTG \\
& qPCR & hPTXqrev & CCATTCCGAGTGCTCCTGA \\
SLC614 & qPCR & hSLC6A14qfor & ACCGTGGTAACTGGTCCAAAA \\
& qPCR & hSLC6A14qrev & CGCCTCCACCATTGCTGTAG \\
& qPCR & TBP_Q_F & GAATATAATCCCAAGCGGTTTG \\
TMEM27 & qPCR & TBP_Q_R & ACTTCACATCACAGCTCCCC \\
& qPCR & hTMEM27qfor & CTGGTGACTGCCATTCATGCT \\
& qPCR & hTMEM27qrev & CCATCGCTTTGAAGAGGTATTCT \\
\hline
\end{tabular}

used to produce Wig files that were converted to TDF files for Integrative Genomics Viewer (IGV) visualization. The HRE location was searched by the "Find Motif" function in IGV with pattern "RCGTG".

\section{HIF-3a overexpression and knockdown experiments and EPO-ELISA}

For HIF- $\alpha$ overexpression EPO-ELISA experiments, 140,000 Hep3B cells were transfected with $1200 \mathrm{ng}$ of either pcDNA3.1-V5-HisA, HIF-3 $\alpha 2$-V5, HIF- $1 \alpha$ or HIF- $2 \alpha$, and $1000 \mathrm{ng}$ of HIF- $\beta$ plasmids, using FuGENE HD. For SKN-AS cells, 250000 cells were transfected with $900 \mathrm{ng}$ of either pcDNA3.1-V5-HisA, HIF-3 $\alpha 2-\mathrm{V} 5$, HIF- $1 \alpha$ or HIF- $2 \alpha$, and HIF- $\beta$ plasmids using FuGENE HD. For knockdown experiments in the SK-N-AS neuroblastoma cell line, the cells were seeded at 250,000 cells per well and transfected with HIF3A siRNA SR312024B (OriGene, USA) twice at an interval of $24 \mathrm{~h}$ using Lipofectamine RNAiMAX (Invitrogen). After the second transfection, the cells were cultured in $1 \% \mathrm{O}_{2}$ for $24 \mathrm{~h}$. Before isolating the total RNA as described above, the medium was collected and stored at $-20{ }^{\circ} \mathrm{C}$ for EPO-ELISA. EPO-ELISA was carried out using the Quantikine IVD ELISA kit (R\&D Systems, USA) according to manufacturer's instructions. The absorbance was measured by Tecan Infinite m1000 PRO plate reader (Tecan, Austria) using $450 \mathrm{~nm}$ as the primary wavelength and $600 \mathrm{~nm}$ as the reference wavelength.

\section{Dual luciferase reporter assay}

45,000 ChoK 1 cells were co-transfected once with $200 \mathrm{ng}$ of wild-type EPO, ANGPTL4, HIST1H2BK, or mutated HIST1H2BK luciferase reporters with HIF- $1 \alpha$, HIF- $2 \alpha$, or HIF-3 $\alpha 2-V 5$ plasmids at one (100 ng) or twoconcentrations (100 ng and $300 \mathrm{ng}$ ) as indicated, with or without $200 \mathrm{ng}$ of the HIF- $\beta$ overexpression plasmid. The empty pcDNA3.1 vector was used to balance the amount of transfected DNA. The pRL-CMV Renilla luciferase reporter was transfected for normalization at $10 \mathrm{ng}$. FuGENE HD (Promega) was used as transfection reagent. The cells were cultured under normoxic conditions for $24 \mathrm{~h}$. The luciferase protein samples were prepared using the Dual-Luciferase Reporter Assay System (Promega) according to manufacturer's instructions and analyzed using the Varioskan LUX plate reader (Thermo Fisher Scientific).

\section{Statistical analysis}

Data are presented as means $( \pm$ SD). Statistical analyses were carried out using the two-tailed Student's $t$ test using GraphPad Prism (version 7.03). Values of $p<0.05$ are considered statistically significant, with $*$ or \# denoting $p<0.05$, ** or \#\# $p<0.01$, and *** or \#\#\# $p<0.001$.

\section{Results}

\section{Identification of HIF-3 target genes by microarray analysis}

HIF-3 $\alpha$ has previously been considered mainly as a dominant inhibitor of the hypoxia response by competitive binding of the other HIF- $\alpha$ subunits [5]. However, more recent studies have shown that the long human HIF-3 variants possess transactivation activity [9, 12, 30, 31, 35]. siRNA knockdown of all human HIF-3 $\alpha$ variants simultaneously results in downregulation of certain hypoxia-responsive genes such as EPO, GLUT1, and ANGPTL4, and overexpression of long HIF- $3 \alpha$ variants that possess the NTAD under conditions, where HIF- $\beta$ is not limiting has an inducing effect on the same genes, with HIF- $3 \alpha 2$ producing the most robust induction of EPO expression out of the five long HIF-3 $\alpha$ variants [12]. To explore the potentially dual role of HIF-3 in the hypoxia response, we carried out a cDNA microarray screen of HIF-3 $\alpha 2$ overexpression and siRNA knockdown of all HIF3A splice variants in hypoxic Hep3B cells.

Setting the cut-off point of change in the expression level of a gene at $\geq 2$-fold revealed eight upregulated (Fig. 1a) 


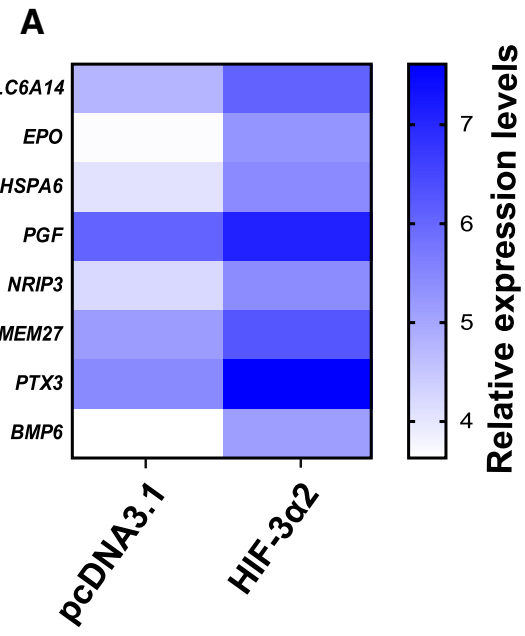

C

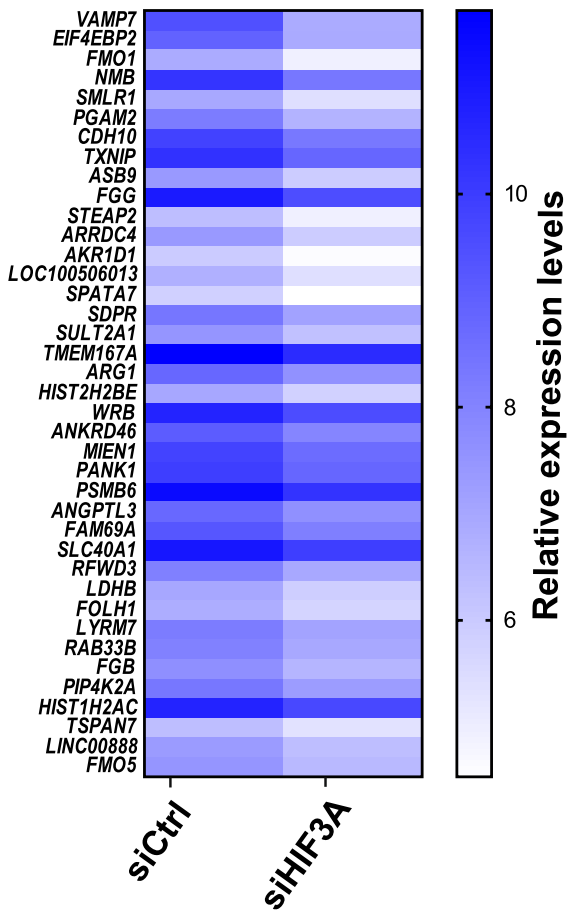

B
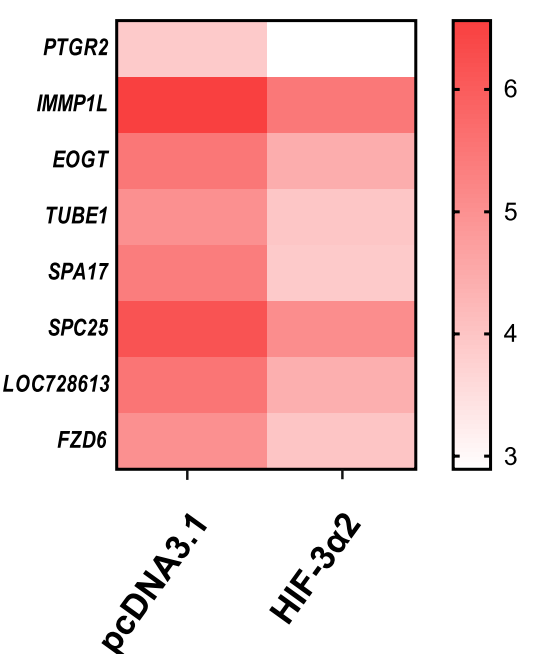

D

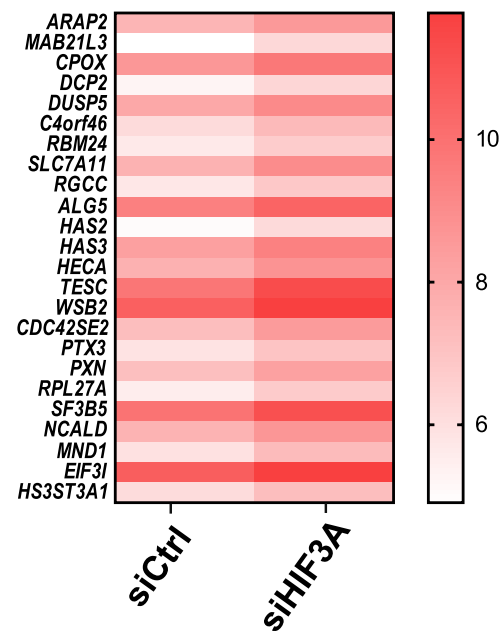

E

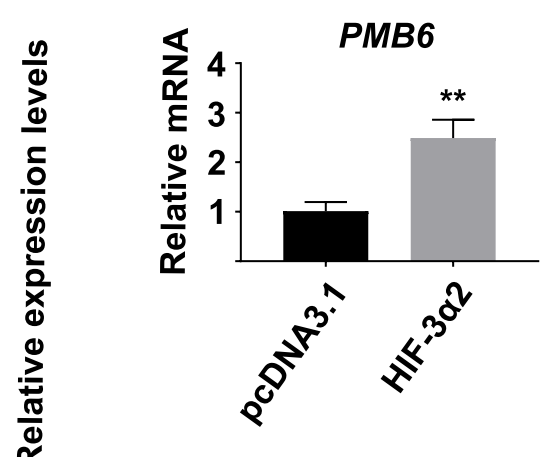

$\mathbf{F}$

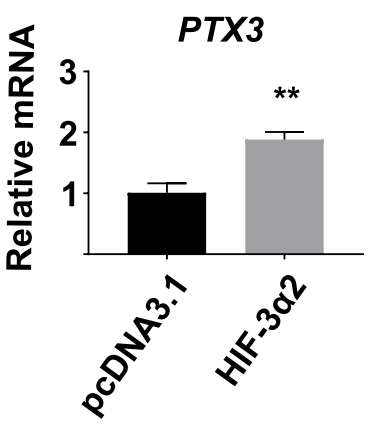

G

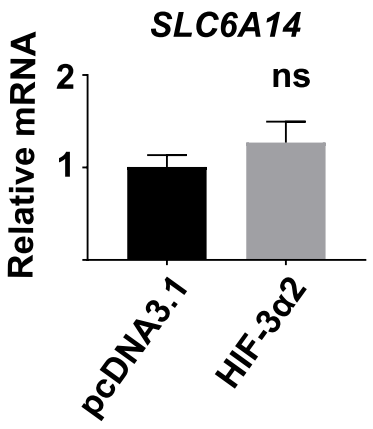

Fig. 1 cDNA microarray screen of hypoxia-dependent HIF-3 target genes. The heatmaps show $\geq 2$-fold upregulated (a) and downregulated (b) genes by HIF-3 $\alpha 2$ and HIF- $\beta$ co-overexpression, and downregulated (c) and upregulated (d) genes by HIF3A siRNA treatment in Hep3B cells incubated for $24 \mathrm{~h}$ in $1 \%$ hypoxia. The heatmaps are based on six pooled biological replicates on two microarray chips and show relative linear expression levels for control and treated cells as indicated. Darker shades of blue and red indicate higher levels of expression. e-g Validation of BMP6, PTX3 and SLC6A14 expression levels by qPCR with HIF- $3 \alpha 2$ and HIF- $\beta$ co-overexpression in Hep3B cells incubated in $1 \%$ hypoxia for $24 \mathrm{~h}$. The qPCR data show upregulation of target genes that is in line with the microarray data. The mRNA levels are shown relative to TBP mRNA. Data are represented as means $( \pm \mathrm{SD})$ from three independent experiments, $n=3$. $* * p<0.01$, two-tailed Student's $t$ test

pentraxin 3 (PTX3), and solute carrier family 6 member 14 (SLC6A14) among others. In contrast, the eight genes downregulated by HIF-3 $\alpha 2$ overexpression include sperm autoantigenic protein 17 (SPA17) and frizzled family receptor 6 (FZD6), among others. 
Next, treating Hep3B cells with either control siRNA or siRNA targeting all HIF3A splice variants and incubating the cells in $1 \%$ hypoxia for $24 \mathrm{~h}$ revealed a downregulation of 39 genes with $\geq 2$-fold change (Fig. 1c). These genes include vesicle-associated membrane protein 7 (VAMP7), thioredoxin interacting protein $(T X N I P)$, proteasome subunit type 6 (PSMB6), and angiopoietin-like 3 (ANGPTL3), among others. In comparison, 24 genes were upregulated $\geq 2$-fold by siHIF3A knockdown (Fig. 1d), including tescalcin (TESC), solute carrier family 7 member 11 (SLC7A11), and eukaryotic translation initiation factor 3, subunit I (EIF3I).

The cDNA microarray data suggest that HIF-3 has both inductive and inhibitory effects on global gene expression.
As the microarray analysis setup was designed to provide an initial screen of the effects of HIF-3 on gene expression, it should only be taken as indicative. To verify the changes observed by HIF- $3 \alpha 2$ and HIF- $\beta$ co-overexpression on cDNA microarray, the upregulation of a subset of genes was confirmed by qPCR. HIF- $3 \alpha 2$ overexpression produces an upregulation of $B M P 6(2.5( \pm 0.37)$-fold, Fig. 1e) and PTX3 (1.9 ( \pm 0.13$)$-fold, Fig. 1f) but not of SLC6A14 (Fig. 1g). Similarly, EPO expression was validated on mRNA and protein levels (Fig. 2). Of note, EPO is expressed at a low level in Hep3B cells and thus only appears on the HIF-3 $\alpha 2$ overexpression microarray.
Fig. 2 EPO regulation by HIF-3 in two cell lines. EPO mRNA and protein levels are upregulated by HIF- $\alpha$ overexpression in Hep3B (a, b) and SK-N-AS cells $(\mathbf{c}, \mathbf{d})$ when co-transfected with HIF- $\beta$. Treating SK-N-AS cells with siRNA targeting all $H I F 3 A$ variants results in statistically significant downregulation of EPO mRNA and protein levels $(\mathbf{e}, \mathbf{f})$. Fold changes are relative to cells co-transfected with empty pcDNA3.1-V5HisA vector and HIF- $\beta$, or control siRNA. EPO mRNA levels are relative to $T B P$ for Hep3B cells, and $A C T B$ and HPRT1 for SK-N-AS cells. Data represent means $( \pm S D)$ from three independent experiments, $n=6-9$. * $p<0.05, * * p<0.01$, $* * * p<0.001$, two-tailed Student's $t$ test
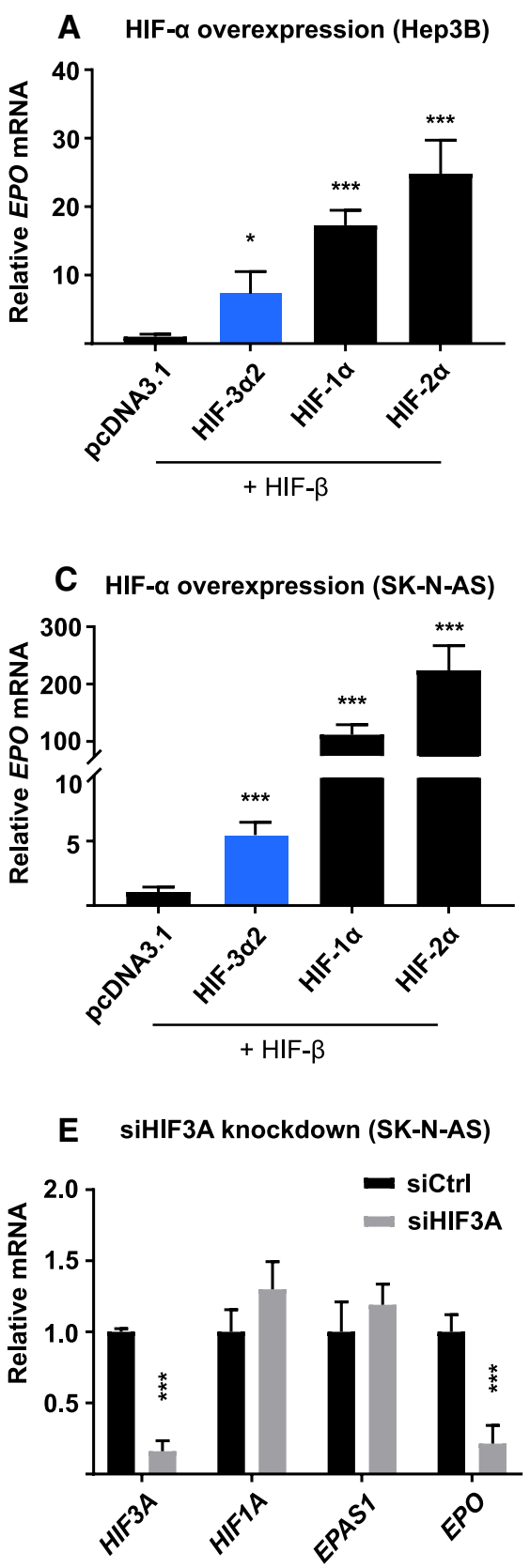
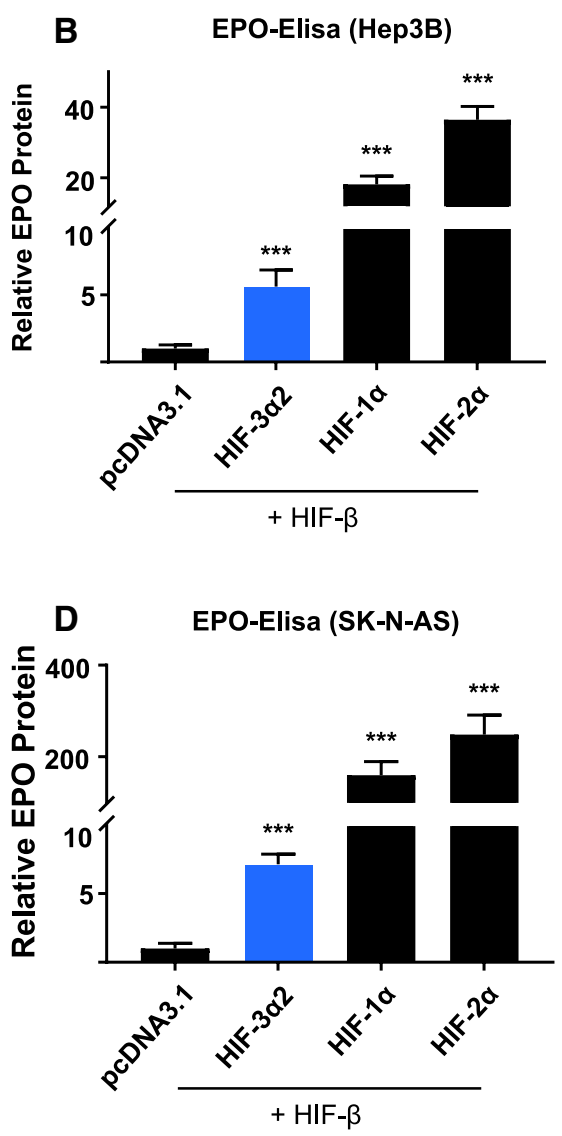

F SiHIF3A EPO-Elisa (SK-N-AS)

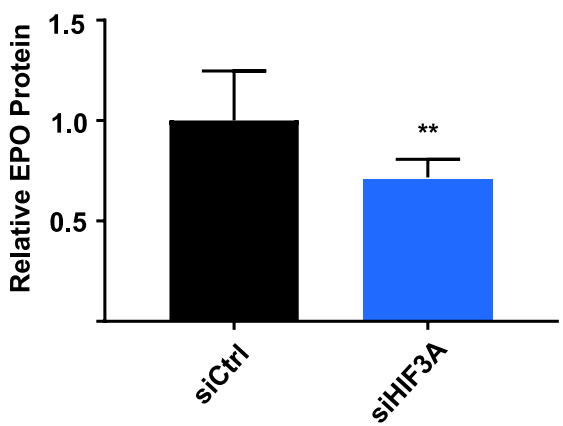


Finally, functional enrichment analyses were carried out with Chipster [33]. Setting the cut-off point at $66 \%$ upregulation by HIF- $3 \alpha 2$ and HIF- $\beta$ co-overexpression revealed an upregulation of 59 genes. GO enrichment analyses suggest that HIF-3 $\alpha 2$ is involved in DNA replication-dependent nucleosome assembly, vascular endothelial growth factor receptor signaling pathway, urogenital system development, and erythrocyte homeostasis (Table 2). A cut-off point of downregulation by $40 \%$ upon siHIF3A treatment revealed 126 downregulated genes. GO analysis shows enrichment of genes involved in heterotypic cell-cell adhesion, plasminogen activation, negative regulation of endothelial cell apoptotic process, blood coagulation, and fibrin clot formation as well as fibrinolysis (Table 3).

\section{The expression of EPO correlates with the knockdown of HIF3A and overexpression of HIF-3a2}

As the microarray data indicate upregulation of EPO by HIF-3 $\alpha 2$ overexpression (Fig. 1a), and as we have previously shown that siRNA knockdown of all HIF3A splice variants results in downregulation of EPO mRNA by $39-60 \%$ and protein by $28-73 \%$ in Hep3B cells [12], we carried out further HIF-3 $\alpha 2$ overexpression experiments in Hep3B and the EPO-producing SK-N-AS neuroblastoma cells, as well as siHIF3A knockdown experiments in the SK-N-AS cells. EPO mRNA was upregulated 7- and 5-fold in Hep3B and SK-N-AS cells, respectively, with HIF-3 $\alpha 2$ overexpression (Fig. 2a, c). In comparison, overexpression of HIF- $1 \alpha$ and HIF- $2 \alpha$ resulted in 17- and 25-fold upregulation of $E P O$ mRNA in Hep3B cells, and in 110- and 220-fold upregulation in SK-N-AS cells, respectively (Fig. 2a, c). A 79\% downregulation of EPO mRNA level was observed in SKN-AS cells with siHIF3A treatment (Fig. 2e). It is highly unlikely that this was due to non-specific knockdown of $H I F 1 A$ or HIF2A, as their mRNA levels were unchanged (Fig. 2e). Of note, previous experiments using siRNA targeting HIF 1A mRNA in Hep3B cells, Kelly neuroblastoma cells, and cortical astrocytes haveshown no effect on $E P O$ expression [23, 27].

Changes in EPO expression were then analyzed at protein level by ELISA. Overexpression of HIF- $3 \alpha 2$, HIF- $1 \alpha$, or HIF- $2 \alpha$ resulted in sevenfold, 160 -fold and 250 -fold
Table 2 Gene ontology (GO) functional analysis of upregulated genes by HIF- $3 \alpha 2$ overexpression in Hep3B cells

Table 3 Gene Ontology (GO) functional analysis of downregulated genes by siHIF3A treatment of Hep3B cells

\begin{tabular}{lll}
\hline GO term & $p$ value & Description \\
\hline GO:0072163 & 0.00042 & Mesonephric epithelium development \\
GO:0033189 & 0.00193 & Response to vitamin A \\
GO:0006335 & 0.00283 & DNA replication-dependent nucleosome assembly \\
GO:0048010 & 0.00295 & Vascular endothelial growth factor receptor signaling pathway \\
GO:0055093 & 0.00389 & Response to hyperoxemia \\
GO:0000188 & 0.00418 & Inactivation of MAPK activity \\
GO:0001655 & 0.00458 & Urogenital system development \\
GO:0034101 & 0.00554 & Erythrocyte hemostasis \\
GO:0001657 & 0.00571 & Ureteric bud development \\
GO:0032094 & 0.0061 & Response to food \\
GO:0032094 & 0.00648 & Positive regulation of bone mineralization \\
GO:1901532 & 0.00722 & Regulation of hematopoietic progenitor cell differentiation \\
\hline
\end{tabular}

\begin{tabular}{|c|c|c|}
\hline GO term & $p$ value & Description \\
\hline GO:0034116 & 0.00019 & Positive regulation of heterotypic cell-cell adhesion \\
\hline GO:0045921 & 0.00042 & Positive regulation of exocytosis \\
\hline GO:0043436 & 0.00066 & Oxoacid metabolic process \\
\hline GO:0031639 & 0.00079 & Plasminogen activation \\
\hline GO: 1902042 & 0.00096 & $\begin{array}{l}\text { Negative regulation of extrinsic apoptotic signaling pathway via } \\
\text { death domain receptors }\end{array}$ \\
\hline GO:2000352 & 0.00115 & Negative regulation of endothelial apoptotic process \\
\hline GO:0072378 & 0.0124 & Blood coagulation, fibrin clot formation \\
\hline GO:0042730 & 0.00145 & Fibrinolysis \\
\hline GO:0051592 & 0.00152 & Response to calcium ion \\
\hline GO:1900026 & 0.00156 & Positive regulation of substrate adhesion-dependent cell spreading \\
\hline
\end{tabular}


increases in EPO protein level in SK-N-AS cells, respectively (Fig. 2d). In Hep3B cells, similar treatment resulted in sixfold, 18-fold and 36-fold changes, respectively (Fig. 2b). Treating SK-N-AS cells with siRNA targeting all HIF3A splice variants resulted in downregulation of EPO protein level by $28 \%$ (Fig. 2f), which is in line with previous results obtained in Hep3B cells [12].

Next, to assess whether HIF3A mRNA is expressed at a biologically relevant level, we compared the mRNA abundances of the three HIF- $\alpha$ isoforms by qPCR in normoxic Hep3B cells and Hep3B cells that were incubated in $1 \%$ hypoxia for $24 \mathrm{~h}$. As expected, the HIF3A mRNA is induced by $73 \%$ in hypoxia (Fig. 3a). Previous studies have shown that this hypoxic induction is HIF-1 dependent $[9,10]$. In both normoxic and hypoxic Hep3B cells, HIF- $1 \alpha$ is the predominant HIF- $\alpha$ isoform with a 240-300-fold abundance over HIF3A mRNA (Fig. 3a). However, hypoxic Hep3B cells express HIF-3 $\alpha$ and HIF- $2 \alpha$ mRNA at a 1:2 ratio (Fig. 3a). The data-especially that of HIFIA expression-are to be treated with caution as differences in primer efficiencies cannot be excluded.

Finally, to explore whether co-overexpression of HIF- $2 \alpha$ and HIF- $3 \alpha 2$ with or without HIF- $\beta$ alters $E P O$ expression, we transfected Hep3B cells with the HIF- $\alpha$ and HIF- $\beta$ overexpression plasmids as indicated and measured $E P O$ mRNA abundances by qPCR (Fig. 3b). Of note, the pcDNA3.1/ Zeo(-) backbone produces an upregulation of HIF- $\alpha$ mRNA

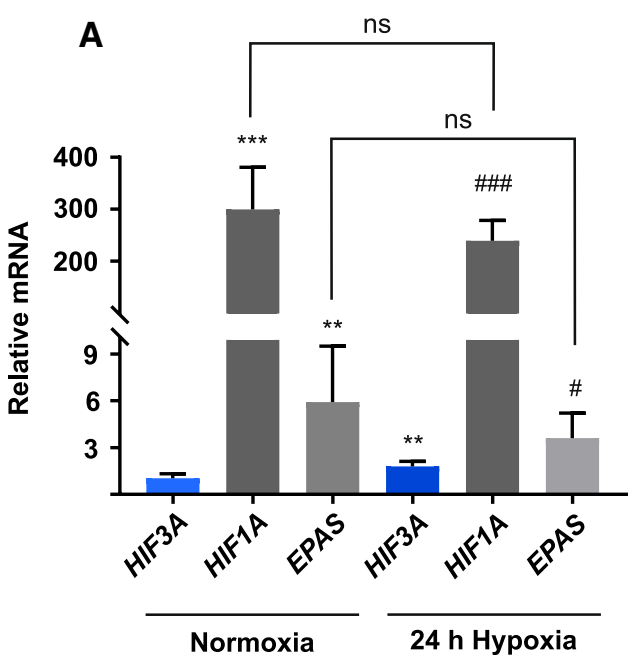

Fig. 3 Hypoxic Hep3B cells express HIF-2 $\alpha$ and HIF-3 $\alpha$ at considerably lower levels than HIF-1 $\alpha$. a Hep3B cells were incubated in normoxia $\left(\mathrm{pO}_{2} 21 \%\right)$ and $1 \%$ hypoxia for $24 \mathrm{~h}$ before isolation of mRNA and quantification by qPCR. HIF- $1 \alpha$ mRNA is 240 to 300 -fold more abundant than HIF- $3 \alpha$ mRNA, while HIF- $2 \alpha$ mRNA abundance is only 2 -fold higher than that of HIF- $3 \alpha$ in hypoxia. HIF-3 $\alpha$ expression is induced by hypoxia. Data are represented as means $( \pm \mathrm{SD})$ from three independent experiments, $n=6 .{ }^{* *} p<0.01$, $* * * p<0.001$ against HIF3A mRNA abundance in normoxia, ${ }^{\#} p<0.05,{ }^{\# \#} p<0.001$ against HIF3A mRNA abundance in $1 \%$ hypoxia, two-tailed Student's by a fold of a few hundred, which most likely saturates $E P O$ expression. No statistically significant changes were observed in $E P O$ expression with or without HIF- $\beta$ upon co-overexpression of HIF- $2 \alpha$ and HIF-3 32 (Fig. 3b). Based on these findings, it is unlikely that HIF- $3 \alpha 2$ acts as a dominant inhibitor of HIF-2 $\alpha$ in the context of EPO expression.

\section{The long HIF-3 a $\beta$ dimer binds target gene promoters via the canonical HRE}

To analyze HIF-3 binding to its target genes, we performed ChIP-seq analysis after HIF- $3 \alpha 2$ and HIF- $\beta$ co-overexpression in Hep3B cells. De novo motif analysis of the peaks shows that the most significant motif for HIF- $3 \alpha 2$ enrichment is the canonical HRE core sequence, $5^{\prime}$-RCGTG-3', with the $\mathrm{R}$ position showing preference for adenine (Fig. 4a). The motif is shared most significantly by HIF- $\beta$. Overall, the data show that the HIF- $3 \alpha 2$ peaks are enriched in the promoter regions (data not shown, GSE129491).

Next, ChIP-seq shows enrichment for HIF-3 $\alpha 2$ in the promoter-TSS within the 0.4-kb 5'-flanking region of $E P O$, and some enrichment $3^{\prime}$ end to intron 1 (Fig. 4b), a region involved in liver-specific expression [19, 20]. Enrichment is not evident immediately at $3^{\prime}$ end of EPO on the 256-bp LIE (Fig. 4b) which has been identified as a crucial site for HIF-2, but not HIF-1, driven $E P O$ regulation in the liver $[20,22,23]$. The 5 '-flanking enrichment site contains six

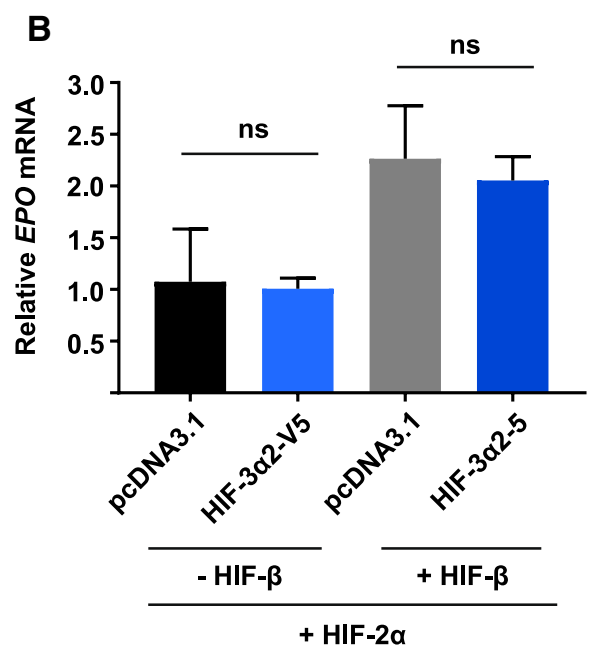

$t$ test. b Hep3B cells were transfected with the HIF-2 $\alpha$ overexpression plasmid together with either the empty pcDNA3.1 vector or the HIF- $3 \alpha 2$ overexpression plasmid, and with or without the HIF- $\beta$ overexpression plasmid as indicated, and incubated in $1 \%$ hypoxia for 24 h. Co-overexpression of HIF-3 32 does not induce or inhibit $E P O$ expression upon HIF- $2 \alpha$ overexpression. However, co-overexpression of HIF- $\beta$ doubles EPO mRNA abundance. Data are represented as means $( \pm \mathrm{SD})$ from three independent experiments, $n=3$. ${ }^{*} p<0.05$, ${ }^{* *} p<0.01$, two-tailed Student's $t$ test 
A

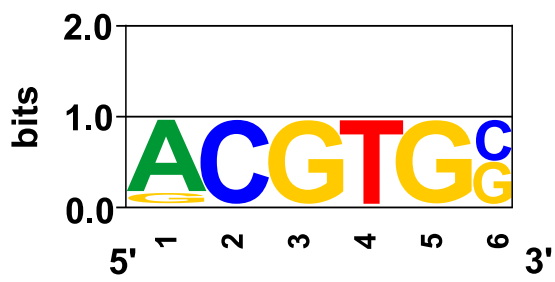

B

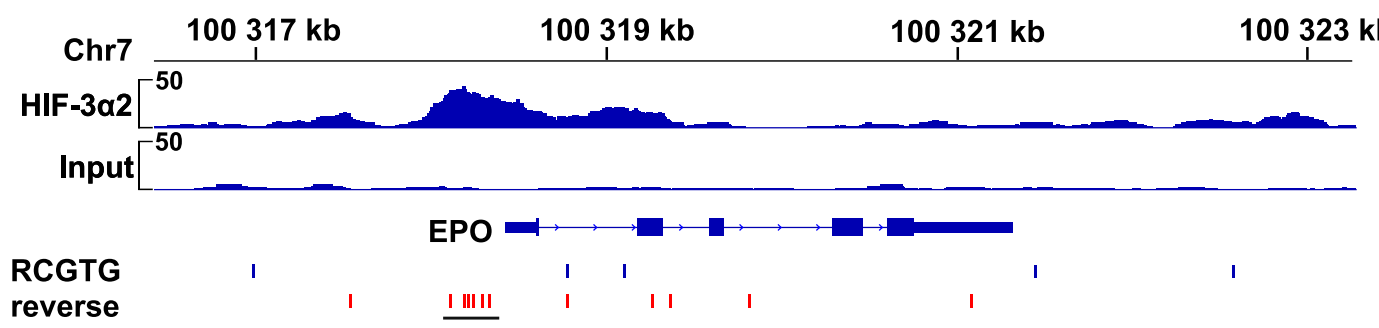

C

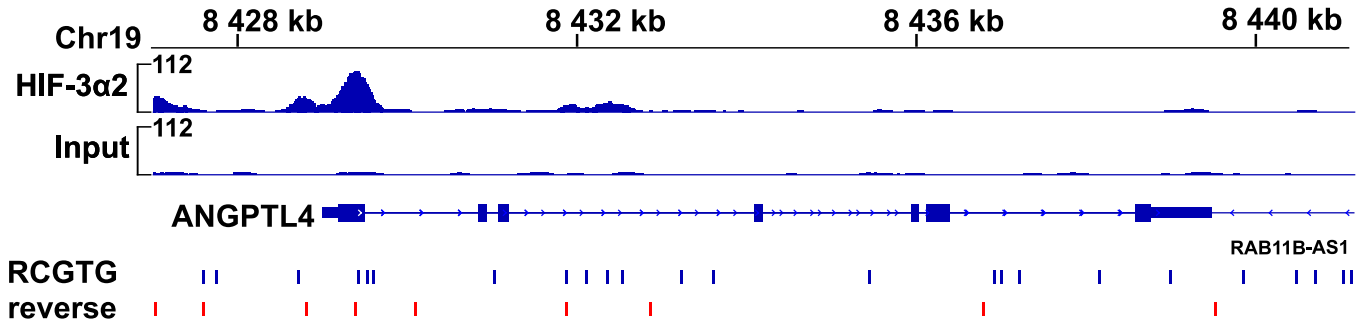

D

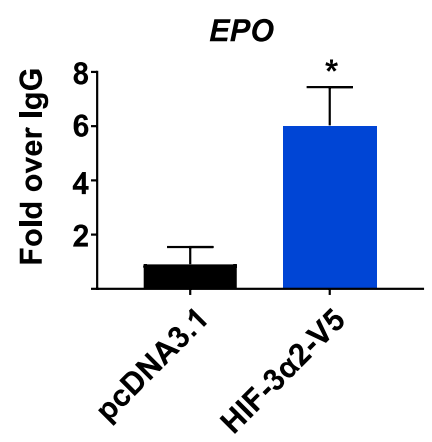

G

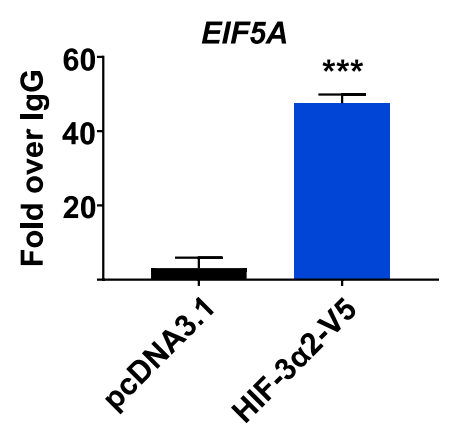

E

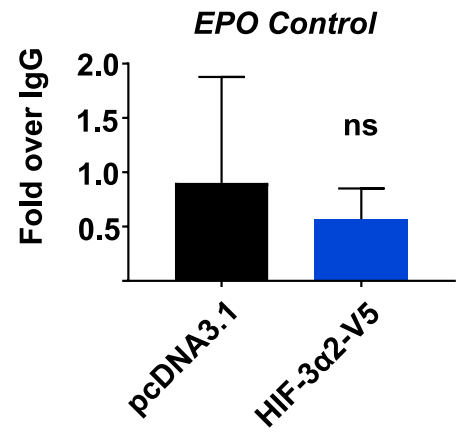

H

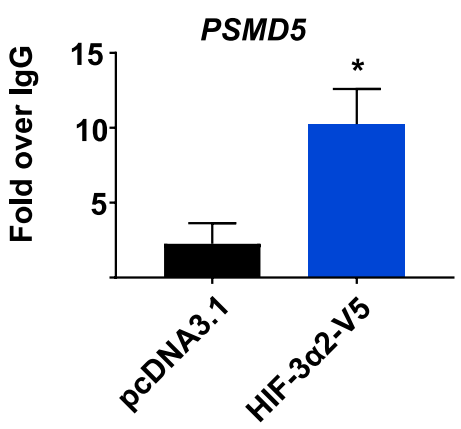

F
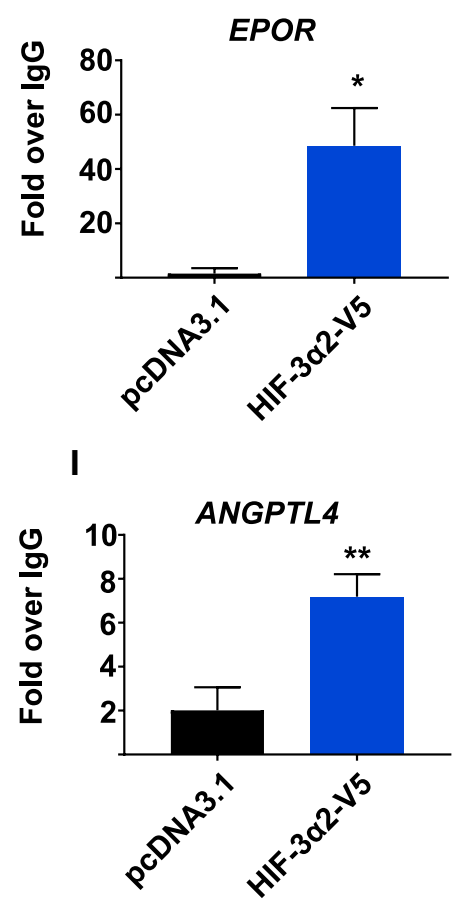
4Fig. 4 HIF-3 binding is associated with the canonical HRE in the promoter regions of its target genes. a HIF-3 $\alpha 2$ ChIP-seq enrichment signal associates with the canonical HRE sequence with preference for A at position R. b, c HIF-3 22 enrichment is observed on the EPO and ANGPTL4 genes near the promoter-TSS, co-localizing with sites that contain six canonical HRE sequences (5'-RCGTG-3', included HREs underlined) on forward and reverse strands as denoted by blue and red lines, respectively. Interestingly, no HIF-3 32 enrichment is detected on the LIE immediately $3^{\prime}$ to EPO. HIF-3 $\alpha 2$ enrichment (first track) is shown relative to input (lower track). Samples were prepared in triplicate and pooled for ChIP. $\mathbf{d}-\mathbf{i}$ Validation of a subset of HIF-3 $\alpha 2$ chromatin-binding enrichment sites by ChIP-qPCR. ChIP-qPCR by HIF3A and normal rabbit IgG antibodies shows amplification in the HIF-3 $\alpha 2$ enrichment site on five genes, namely EPO (d), EPOR (f), EIF5A (g), PSMD5 (h), and ANGPTL4 (i), and no amplification with a control primer set designed to target regions of $E P O$ where no enrichment is observed (e), $n=3$. The ChIP-qPCR results are normalized with respect to input. $* p<0.05$, $* * p<0.01$, $* * * p<0.001$, two-tailed Student's $t$ test

canonical HREs on the reverse strand, showing HIF-3 22 binding mainly across the first four HREs. In contrast, the LIE contains only a single HRE. Although the ANGPTL4 gene does not show up on the cDNA microarray data, previous studies have shown that its hypoxic induction is HIF-3 dependent $[9,12]$, and thus, we decided to pursue it further on ChIP-seq. Two chromatin regions of enrichment for HIF-3 $\alpha 2$ are detected near the promoter-TSS of ANGPTL4, $290 \mathrm{bp}$ upstream and $380 \mathrm{bp}$ downstream from the TSS (Fig. 4c). The downstream HIF-3 $\alpha 2$-enriched region contains up to four canonical HREs.

Finally, we validated the ChIP-seq data by ChIP-qPCR with primer sets designed to span the HIF-3 binding regions. ChIP-qPCR shows relative enrichment of HIF-3 22 occupancy over IgG using primer sets for EPO $[6.0( \pm 1.4)$ fold], EPOR [48.6 ( \pm 13.9$)$-fold], EIF5A [47.5 ( \pm 2.4$)$ fold], PSMD5 [10.2 ( \pm 2.3$)$-fold], and ANGPTL4 [7.2 $( \pm 1.0)$-fold], and no enrichment over $\operatorname{IgG}$ with a primer set designed to target a region of $E P O$, where no HIF-3 binding was observed (Fig. 4d-i).

\section{HIF-3a2 overexpression may result in frivolous HRE-dependent chromatin binding}

To further explore the chromatin binding capacity of the long HIF-3 $\alpha \beta$ dimer, we focused on Histone Cluster 1 H2B Family Member K (HIST1H2BK) as the ChIP-seq data suggest HIF-3 $\alpha 2$ association with this gene. The ChIP-seq analysis revealed an enrichment of HIF- $3 \alpha 2$ occupancy in the promoter region $440 \mathrm{bp}$ upstream from the TSS of HISTIH2BK (Fig. 5a). This region contains four canonical HREs. ChIP-qPCR confirmed HIF-3 $\alpha 2$ binding with a 7.7 ( \pm 2.6 )-fold relative enrichment over IgG (Fig. 5b).

To validate the activity of the $H I S T 1 H 2 B K$ regulatory sequence, we cloned the HIF-3 $\alpha 2$-bound genomic region of HISTIH2BK in front of a luciferase gene in the pGL4.75 vector. The reporter plasmid was co-transfected into ChoK1 cells with either HIF- $1 \alpha$ or HIF- $3 \alpha 2$ at two concentrations (100 ng or $300 \mathrm{ng}$ ) with HIF- $\beta$ and the Renilla reporter for normalization, after which the ChoK1 cells were incubated in normoxia for $24 \mathrm{~h}$. Both HIF- $1 \alpha$ and HIF-3 $\alpha 2$ cooverexpressed with HIF- $\beta$ induce the transcription of the luciferase reporter, with HIF-1 $\alpha$ producing higher levels of luminescence signal in a dose-dependent manner (Fig. 5c). HIF- $3 \alpha 2$ reaches a plateau already at the lower plasmid concentration (Fig. 5c). To study the HRE-dependency for HIF- $1 \alpha$ and HIF- $3 \alpha 2$ binding, we mutated the four HREs in the HISTIH2BK luciferase reporter to 5'-ATTTA-3'. The luminescence signal produced by the mutated HISTIH2BK luciferase reporter with HIF- $1 \alpha$ and HIF- $3 \alpha 2$ overexpression was reduced by $66 \%$ and $69 \%$, respectively, providing further evidence that the HREs are necessary for maximal transcription and are the main but not sole determinant of HIF binding (Fig. 5d).

However, functional studies suggest that the endogenous HIF-3 $\alpha \beta$ dimer may not bind the HISTIH2BK gene. We quantified the HISTIH2BK mRNA levels in normoxic and hypoxic Hep3B cells after incubation in $1 \%$ hypoxia for $24 \mathrm{~h}$. Hypoxia downregulates HISTIH2BK expression by 25\% in Hep3B cells (Fig. 5e). Finally, treating Hep3B cells with control siRNA or siRNA targeting all HIF3A splice variants and incubating the cells in $1 \%$ hypoxia for $24 \mathrm{~h}$ shows that $H I F 3 A$ silencing produces an upregulation of HISTIH2BK by $65 \%$ (Fig. 5f). Therefore, it is possible that some of the HIF-3 $\alpha 2$ occupancy observed on ChIP-seq is a result of overexpression and may not reflect endogenous function highlighting the importance of validation of the data at an endogenous level.

\section{Synergistic activity at the EPO promoter with HIF-3a2 and HIF-1 $a$ or HIF-2a co-overexpression}

In contrast to the $H I S T 1 H 2 B K$ gene, functional experiments in the Hep3B and SK-N-AS cell lines suggest that the long HIF-3 $\alpha \beta$ dimer is involved in the regulation of EPO expression, whereas ChIP assays demonstrate that this regulation is via direct chromatin binding. To validate the activity of the regulatory sequence in the $E P O$ promoter, we cloned the HIF-3 $\alpha 2$-bound genomic region into the pGL4.75 luciferase vector. The $E P O$ luciferase reporter was then co-transfected into ChoK 1 cells with one of the HIF- $\alpha$ isoform overexpression plasmids, the Renilla reporter for normalization, and either the empty pcDNA3.1/Zeo(-) vector or the HIF- $\beta$ overexpression plasmid. Next, the cells were incubated in normoxia for $24 \mathrm{~h}$. Both HIF- $1 \alpha$ and HIF- $2 \alpha$ can induce the transcription of the luciferase reporter without HIF- $\beta$, with HIF- $1 \alpha$ producing a $20 \%$ increase and HIF- $2 \alpha$ producing up to a $3( \pm 0.41)$-fold increase over the control cells (Fig. 6a). 

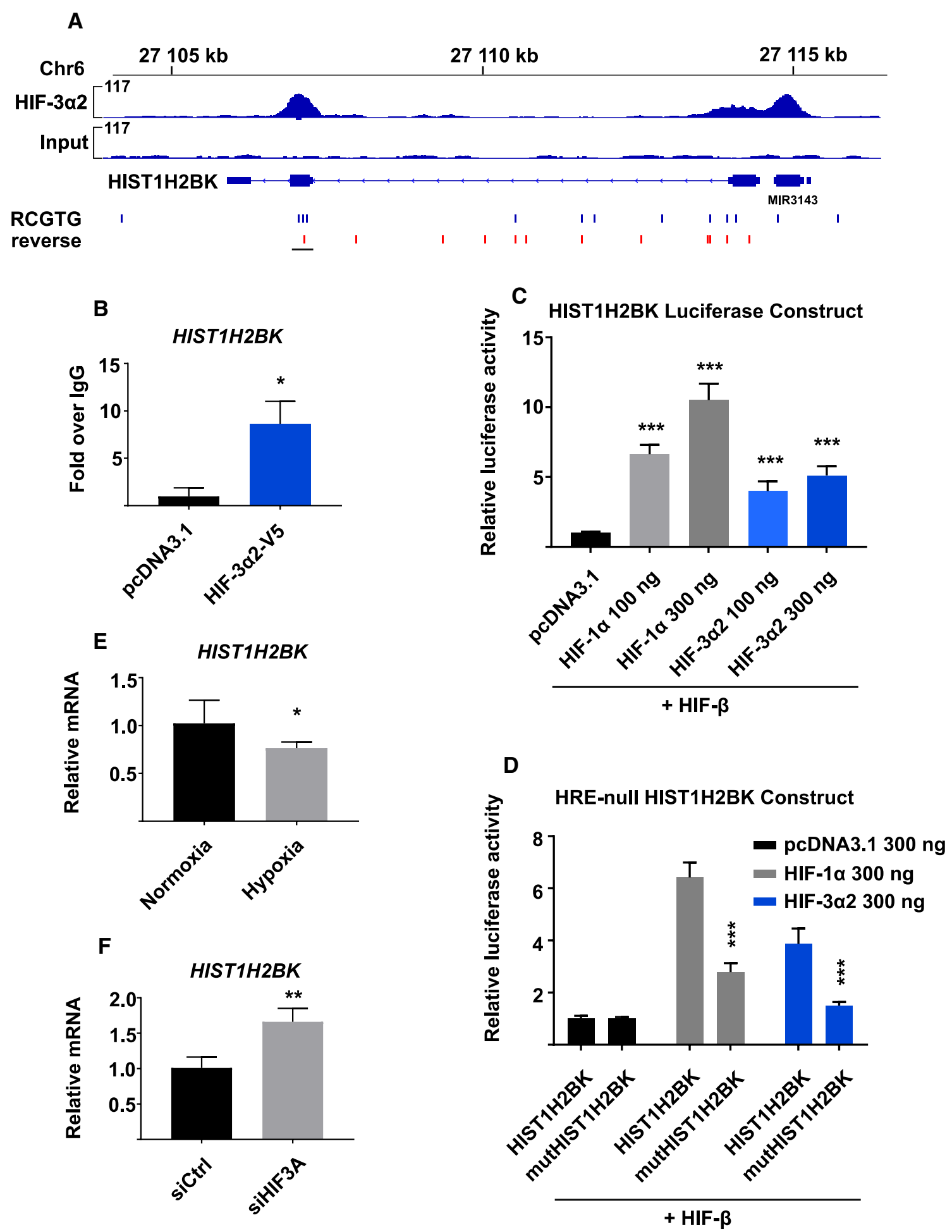

With a co-overexpression of HIF- $\beta$, all HIF- $\alpha$ isoforms can induce the $E P O$ luciferase reporter by 34.2 ( \pm 9.1 )-fold, 41.6 $( \pm 4.5)$-fold, and $9.0( \pm 2.3)$-fold for HIF-1 $\alpha$, HIF-2 $\alpha$, and HIF-3 $\alpha 2$, respectively (Fig. 6b).

Finally, to further explore the transactivation capacity of HIF-3 $\alpha 2$, we co-overexpressed HIF-3 $\alpha 2$ with HIF- $1 \alpha$

or HIF- $2 \alpha$ and measured the relative luciferase activity produced by the EPO luciferase reporter. Without HIF- $\beta$, HIF-3 32 induced the relative luciferase activity by $17 \%$ and $21 \%$ over HIF- $1 \alpha$ or HIF- $2 \alpha$ alone, respectively (Fig. $6 \mathrm{c}$, d). With HIF- $\beta$, however, a co-overexpression of HIF- $1 \alpha$ or HIF-2 $\alpha$ with HIF-3 $\alpha 2$ produced a $45.6( \pm 10.4)$-fold and 
४Fig. 5 HIF-3 $\alpha 2$ overexpression may result in frivolous HRE-dependent chromatin binding. a ChIP-seq shows HIF-3 22 enrichment on the HISTIH2BK gene near the promoter-TSS, co-localizing with a site that contains four canonical HRE sequences. b ChIP-qPCR confirmation of HIF-3 $\alpha 2$ binding on HISTIH2BK. c Luciferase reporter construct containing the HIF- $3 \alpha 2$ enrichment site on HIST1H2BK shows statistically significant upregulation by HIF- $1 \alpha$ and HIF- $3 \alpha 2$. Induction by HIF-3 22 plateaus already at the lower $100 \mathrm{ng}$ transfection dosage. The data represent means $( \pm \mathrm{SD})$ from three independent experiments, $n=8-9$. d Four HREs observed in the HIF-3 $\alpha_{2}$ enrichment site on HIST1H2BK were mutated to $5^{\prime}$-ATTTA-3' to study the HRE-dependency of HIF- $3 \alpha 2$ and HIF- $1 \alpha$ binding, showing 66-69\% decrease in luminescence signal. The data represent means ( \pm SD) from four independent experiments, $n=11-12$. e Hep3B cells were incubated in normoxia $\left(\mathrm{pO}_{2} 21 \%\right)$ and $1 \%$ hypoxia to study the hypoxia-dependent expression of HISTIH2BK. Hypoxia downregulates $H I S T 1 H 2 B K$ expression by $25 \%$, representing means $( \pm$ SD) from three independent experiments, $n=6$. f Hep3B cells were treated with control siRNA or siRNA targeting all splice variants of the HIF3A locus, and incubated in $1 \%$ hypoxia for $24 \mathrm{~h}$. HIF $3 A$ knockdown upregulates $H I S T 1 H 2 B K$ expression by $65 \%$. The data represent means $( \pm \mathrm{SD})$ from three independent experiments, $n=3$. ${ }^{*} p<0.05,{ }^{*} p<0.01, * * * p<0.001$, two-tailed Student's $t$ test

$59.6( \pm 14.0)$-fold increase in the relative luciferase activity meaning that HIF- $3 \alpha 2$ induced the luciferase activity by $34 \%$ and $44 \%$ over HIF- $1 \alpha$ or HIF- $2 \alpha$ alone, respectively (Fig. 6c, d).

\section{Discussion}

The contributions of HIF-3 and especially those of the long HIF-3 $\alpha$ splicing variants to the regulation of the hypoxia response are yet largely unknown. We set out here to study the transactivation capacity of HIF- $3 \alpha 2$ in more detail. Among the long HIF-3 $\alpha$ variants, HIF- $3 \alpha 2$ has been previously shown to induce the highest upregulation of $E P O$ mRNA in Hep3B cells; HIF-3 $\alpha 2$ is also expressed in the fetal and adult liver and kidney, which are the main EPO producing tissues $[10,12]$. We explored HIF-3 target genes by cDNA microarray analysis in Hep3B cells and concluded that eight genes were upregulated by $\geq 2$-fold with HIF-3 $\alpha 2$ overexpression and 39 genes were downregulated by $\geq 2$-fold with siHIF3A treatment suggesting a HIF-3 specific transcriptional program. No overlap is observed between these microarray data, because the HIF3A siRNA result in a knockdown of all HIF- $3 \alpha$ splice variants, while the overexpression experiments include only HIF-3 $\alpha 2$. However, both knockdown and overexpression settings result in positive and negative effects on global gene expression suggesting that HIF-3 plays a dual role in the hypoxia response. In the context of overall hypoxia-dependent gene regulation, this can be considered a small subset of genes as HIF-1 and HIF-2 have been shown to regulate the transcription of over 1500 human genes through direct transactivation according to different ChIP assays [14, 15, 36, 37]. In zebrafish, the overexpression of the long Hif-3 splice variant resulted in the upregulation of 136 unique genes, whereas Hif- $1 \alpha$ overexpression upregulated up to 690 genes with 97 overlapping targets [30], supporting the view that HIF-3 is responsible for the oxygen-dependent regulation of a relatively small subset of hypoxia-inducible genes.

We validated the role of HIF-3 in regulating EPO signaling in vitro. We have previously shown that siRNA knockdown of all HIF3A splice variants simultaneously results in the downregulation of EPO mRNA in the Hep3B cell line [12] that was originally used to study the hypoxia-dependent regulation of $E P O$ [19]. Here, we show using Hep3B and SK-N-AS, two cell lines capable of endogenous $E P O$ production, that loss and overexpression of HIF-3 results in significant changes in $E P O$ mRNA and protein levels, further indicating that HIF-3 has a role in erythropoiesis through $E P O$ regulation. Of note, previous studies using siRNA to target HIFIA mRNA in similar cell lines have not produced significant effects in EPO expression [23, 27]. In the murine cardiomyocytes, the knockdown of Hif3a has been associated with a very minor upregulation of $E P O$ expression, but an upregulation of HIF- $1 \alpha$ and HIF- $2 \alpha$ mRNA was also observed [38]. No human kidney-derived cell lines with inducible $E P O$ expression exist, while the derivation of a murine kidney cell line with inducible $E P O$ expression was reported only recently [39].

The last line of evidence supporting our hypothesis that HIF-3 is a transcription activator involved in the regulation of EPO signaling arises from ChIP and transactivation studies. In Hep3B cells, HIF-3 $\alpha 2$ binds chromatin immediately $5^{\prime}$ to the $E P O$ gene, and this genomic region is sufficient to transactivate a luciferase reporter construct by all three HIF- $\alpha$ isoforms. Interestingly, HIF-3 $\alpha 2$ enrichment is not observed at the single HRE required for HIF-2 driven EPO regulation at the liver inducibility element immediately 3 ' to $E P O$ [17]. This may imply that HIF-3 does not compete for the binding sites used by HIF-1 and HIF-2 as was recently shown to be true between HIF-1 and HIF-2 despite a set of shared target genes $[15,40]$. Finally, using the HISTIH2BK gene, we show that HIF-3 may redistribute to non-endogenous HREs upon overexpression and that chromatin occupancy studies should be paired with functional assays to dissect endogenous target genes.

Our data are in line with previous studies about the biological function of the long HIF-3 isoforms. We have shown that siRNA knockdown of all HIF3A splice variants and overexpression of certain long HIF-3 isoforms downregulate and upregulate, respectively, EPO, ANGPTL4, and GLUT1, but not $V E G F$ which is predominantly a HIF-1 target [12]. Similarly, Zhang and colleagues characterized the role of Hif-3 as transcription activator in the zebrafish, and show that hypoxia and overexpression of human HIF- $3 \alpha 9$ [10] induce $L C 3 C, R E D D 1$ and $S Q R D L$ expression in human 

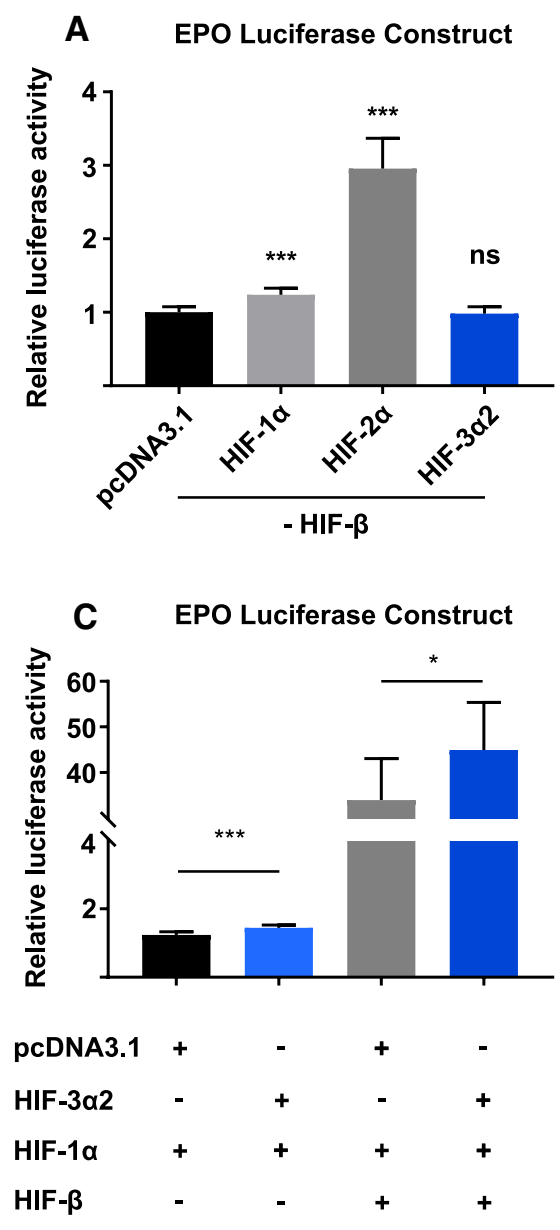

Fig. 6 Synergistic induction of the EPO luciferase reporter by cooverexpression of HIF- $1 \alpha$ or HIF- $2 \alpha$ with HIF- $3 \alpha 2$. a, b ChoK1 cells were transfected with the $E P O$ luciferase reporter containing the HIF-3 $\alpha 2$ binding site near the EPO promoter-TSS and either the HIF-1 $\alpha$, HIF- $2 \alpha$, or HIF-3 32 overexpression plasmid with or without HIF- $\beta$ in normoxia. All three HIF- $\alpha$ isoforms can induce the activity of the $E P O$ luciferase reporter when co-overexpressed with HIF- $\beta$. HIF- $2 \alpha$ produces the most robust upregulation of the reporter. HIF- $\beta$

HEK293 and U2OS cell lines [30]. Furthermore, HIF-3 $\alpha$ has been implicated in the progression of pancreatic cancer by directly binding the promoters of $R H O C$ and $R O C K I$ and transactivating the RhoC-ROCK1 pathway in cancer cells that overexpress HIF3A [41].

The data presented in this study may provide basis for human disease. Two single-nucleotide variants in the HIF3A locus have been associated with familial erythrocytosis [42]. The data reported here suggest that it may be through a direct transactivation effect. However, studies that are more sensitive (i.e., ChIP-seq using antibodies that recognize the endogenous HIF-3 $\alpha$ protein, or RNA-seq to study the kinetics of HIF3A splicing and expression) are required to elucidate the role of HIF-3 further. Next, methylation of the HIF3A gene in blood cells and adipose tissue was recently shown to correlate with increased body-mass

\section{B EPO Luciferase Construct}

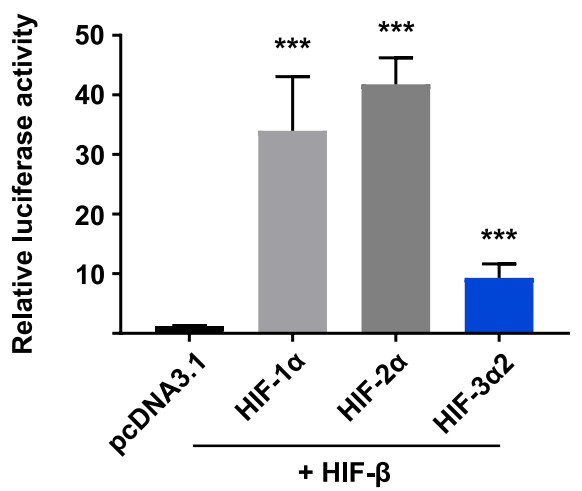

D EPO Luciferase Construct

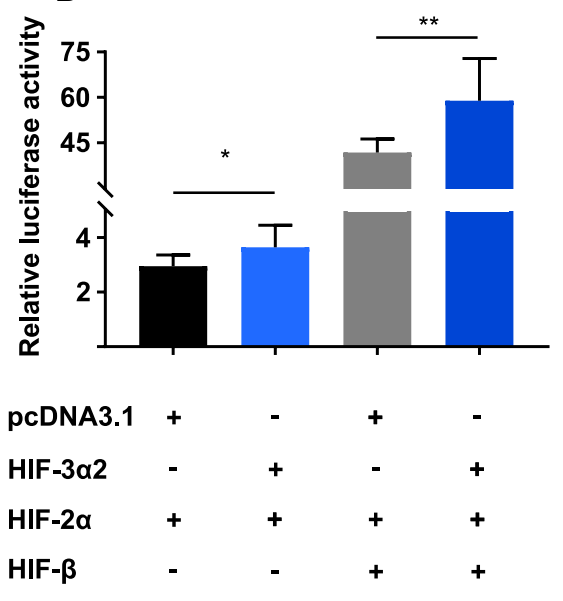

significantly enhances the transactivation capacity of all HIF- $\alpha$ isoforms. The data represent means $( \pm$ SD) from three independent experiments, $n=9$. c, $\mathbf{d}$ Co-overexpression of HIF- $1 \alpha$ or HIF- $2 \alpha$ with $\mathrm{HIF}-3 \alpha 2$ produces a synergistic upregulation of the $E P O$ reporter, representing means $( \pm S D)$ from three independent experiments, $n=9$. The relative luciferase activity is normalized against the pRLCMV Renilla reporter. ${ }^{*} p<0.05, * * p<0.01$, *** $p<0.001$, two-tailed Student's $t$ test

index in a genome-wide association study [43]. The data suggest that impairment of the HIF pathway may result in the dysregulation of body weight, which is in line with previous studies showing that HIF prolyl 4-hydroxylase-2 inhibition and hence HIF- $\alpha$ stabilization and activation of the hypoxia response pathway is protective of obesity and metabolic dysfunction $[44,45]$. We have shown that demethylation increases HIF3A mRNA levels in Hep3B cells [10]. Here, we show that HIF-3 22 directly regulates the expression of ANGPTL4, which is involved in the induction of white adipose tissue lipolysis $[46,47]$ and may thus regulate energy metabolism. Other HIF-3 target genes identified by cDNA microarray, such as ANGPTL3 and PANK1, may also be involved in metabolic regulation [48-51]. This link between HIF-3 and lipid metabolism may also explain why only a few cancer cell lines express the long HIF3A splice 
variants, whereas the HIF- $1 \alpha$ that drives glucose metabolism is their major HIF form [10, 52]. However, further studies are required to elucidate the direct mechanisms of HIF-3 dependent regulation of body weight.

In conclusion, our present study shows that HIF-3 is involved in the regulation of a subset of hypoxia-inducible genes. According to our chromatinimmunoprecipitation data, HIF-3 directly binds EPO in its promoter-TSS at a region harboring several HREs. This region is sufficient to drive the transcription of a luciferase reporter gene. We provide evidence that HIF-3 is a transcription factor required for maximal induction of $E P O$ on mRNA and protein levels, and that HIF- $3 \alpha 2$ is more likely to produce synergistic than inhibitory effects when co-overexpressed with HIF- $1 \alpha$ or HIF- $2 \alpha$. We would, therefore, suggest that the next step in exploring the biological role of HIF-3 is to study murine $H$ if $3 a$ splice variants in $E P O$ regulation in vivo, but it should be noted that splicing of the mouse Hif3a gene is far less complex than that of the human HIF3A gene $[6,7,10,53]$. Therefore, inactivating the individual human HIF3A splice variants using the CRISPR-Cas9 technology or studying the kinetics of HIF3A and HIF- $\beta$ expression through RNA-seq could be preferential approaches for future studies.

Acknowledgements Open access funding provided by University of Oulu including Oulu University Hospital. We thank Anne Kokko for her excellent technical assistance. We are grateful for Professor Peppi Koivunen for providing the SK-N-AS neuroblastoma cell line. This study was supported by the Academy of Finland Project Grant 296498, the Academy of Finland Center of Excellence 2012-2017 Grant 251314, the Sigrid Jusélius Foundation, the Jane and Aatos Erkko Foundation, the Maud Kuistila Memorial Foundation, and FibroGen Inc.

Open Access This article is distributed under the terms of the Creative Commons Attribution 4.0 International License (http://creativeco mmons.org/licenses/by/4.0/), which permits unrestricted use, distribution, and reproduction in any medium, provided you give appropriate credit to the original author(s) and the source, provide a link to the Creative Commons license, and indicate if changes were made.

\section{References}

1. Loenarz C, Coleman ML, Boleininger A, Schierwater B, Holland PWH, Ratcliffe PJ, Schofield CJ (2011) The hypoxia-inducible transcription factor pathway regulates oxygen sensing in the simplest animal, Trichoplax adhaerens. EMBO Rep 12:63-70

2. Semenza GL (2012) Hypoxia-inducible factors in physiology and medicine. Cell 148:399-408

3. Gordan JD, Simon MC (2007) Hypoxia-inducible factors: central regulators of the tumor phenotype. Curr Opin Genet Dev 17:71-77

4. Rankin EB, Giaccia AJ (2008) The role of hypoxia-inducible factors in tumorigenesis. Cell Death Differ 15:678-685

5. Hara S, Hamada J, Kobayashi C, Kondo Y, Imura N (2001) Expression and characterization of hypoxia-inducible factor (HIF)-3 $\alpha$ in human kidney: suppression of HIF-mediated gene expression by HIF-3 $\alpha$. Biochem Biophys Res Commun 287:808-813

6. Makino Y, Cao R, Svensson K, Bertilsson G, Asman M, Tanaka H, Cao Y, Berkenstam A, Poellinger L (2001) Inhibitory PAS domain protein is a negative regulator of hypoxia-inducible gene expression. Nature 414:550-554

7. Makino Y, Kanopka A, Wilson WJ, Tanaka H, Poellinger L (2002) Inhibitory PAS domain protein (IPAS) is a hypoxia-inducible splicing variant of the hypoxia-inducible factor- $3 \alpha$ locus. J Biol Chem 277:32405-32408

8. Maynard MA, Qi H, Chung J, Lee EHL, Kondo Y, Hara S, Conaway RC, Conaway JW, Ohh M (2003) Multiple splice variants of the human HIF-3 $\alpha$ locus are targets of the von Hippel-Lindau E3 ubiquitin ligase complex. J Biol Chem 278:11032-11040

9. Tanaka T, Wiesener M, Bernhardt W, Eckardt K, Warnecke C (2009) The human HIF (hypoxia-inducible factor)- $3 \alpha$ gene is a HIF-1 target gene and may modulate hypoxic gene induction. Biochem J 424:143-151

10. Pasanen A, Heikkilä M, Rautavuoma K, Hirsilä M, Kivirikko KI, Myllyharju J (2010) Hypoxia-inducible factor (HIF)-3 $\alpha$ is subject to extensive alternative splicing in human tissues and cancer cells and is regulated by HIF- 1 but not HIF-2. Int J Biochem Cell Biol 42:1189-1200

11. Pugh CW, O’Rourke JF, Nagao M, Gleadle JM, Ratcliffe PJ (1997) Activation of hypoxia-inducible factor-1; definition of regulatory domains within the $\alpha$ subunit. J Biol Chem 272:11205-11214

12. Heikkilä M, Pasanen A, Kivirikko KI, Myllyharju J (2011) Roles of the human hypoxia-inducible factor (HIF)-3 $\alpha$ variants in the hypoxia response. Cell Mol Life Sci 68:3885-3901

13. Wenger RH, Stiehl DP, Camenisch G (2005) Integration of oxygen signaling at the consensus HRE. Sci STKE 2005(306):re12

14. Schödel J, Oikonomopoulos S, Ragoussis J, Pugh CW, Ratcliffe PJ, Mole DR (2011) High-resolution genome-wide mapping of HIF-binding sites by ChIP-seq. Blood 117:207

15. Smythies JA, Sun M, Masson N, Salama R, Simpson PD, Murray E, Neumann V, Cockman ME, Choudhry H, Ratcliffe PJ, Mole DR (2019) Inherent DNA-binding specificities of the HIF-1 $\alpha$ and HIF- $2 \alpha$ transcription factors in chromatin. EMBO Rep 20(1): e46401

16. Gu YZ, Moran SM, Hogenesch JB, Wartman L, Bradfield CA (1998) Molecular characterization and chromosomal localization of a third alpha-class hypoxia inducible factor subunit, HIF3alpha. Gene Expr 7(3):205-213

17. Haase VH (2013) Regulation of erythropoiesis by hypoxia-inducible factors. Blood Rev 27:41-53

18. Suzuki N (2015) Erythropoietin gene expression: developmentalstage specificity, cell-type specificity, and hypoxia inducibility. Tohoku J Exp Med 235(3):233-240

19. Semenza GL, Dureza RC, Traystman MD, Gearhart JD, Antonarakis SE (1990) Human erythropoietin gene expression in transgenic mice: multiple transcription initiation sites and cis-acting regulatory elements. Mol Cell Biol 10:930-938

20. Semenza GL, Nejfelt MK, Chi SM, Antonarakis SE (1991) Hypoxia-inducible nuclear factors bind to an enhancer element located $3^{\prime}$ to the human erythropoietin gene. Proc Natl Acad Sci USA 88:5680-5684

21. Semenza GL, Koury ST, Nejfelt MK, Gearhart JD, Antonarakis SE (1991) Cell-type-specific and hypoxia-inducible expression of the human erythropoietin gene in transgenic mice. Proc Natl Acad Sci USA 88:8725-8729

22. Rankin EB, Biju MP, Liu Q, Unger TL, Rha J, Johnson RS, Simon MC, Keith B, Haase VH (2007) Hypoxia-inducible factor-2 (HIF-2) regulates hepatic erythropoietin in vivo. J Clin Invest 117:1068-1077

23. Chavez JC, Baranova O, Lin J, Pichiule P (2006) The transcriptional activator hypoxia inducible factor 2 (HIF-2/EPAS-1) 
regulates the oxygen-dependent expression of erythropoietin in cortical astrocytes. J Neurosci 26:9471-9481

24. Storti F, Santambrogio S, Crowther LM, Otto T, Abreu-Rodríguez I, Kaufmann M, Hu C, Dame C, Fandrey J, Wenger RH, Hoogewijs D (2014) A novel distal upstream hypoxia response element regulating oxygen-dependent erythropoietin gene expression. Haematologica 99:45

25. Hirano I, Suzuki N, Yamazaki S, Sekine H, Minegishi N, Shimizu R, Yamamoto M (2017) Renal anemia model mouse established by transgenic rescue with an erythropoietin gene lacking kidneyspecific regulatory elements. Mol Cell, Biol, p 37

26. Shih HM, Wu CJ, Lin SL (2018) Physiology and pathophysiology of renal erythropoietin-producing cells. J Formos Med Assoc 117:888-893

27. Warnecke C, Zaborowska Z, Kurreck J, Erdmann VA, Frei U, Wiesener M, Eckardt KU (2004) Differentiating the functional role of hypoxia-inducible factor (HIF)-1alpha and HIF-2alpha (EPAS-1) by the use of RNA interference: erythropoietin is a HIF-2alpha target gene in Hep3B and Kelly cells. FASEB J. 18(12):1462-1464

28. Kobayashi S, Yamashita T, Ohneda K, Nagano M, Kimura K, Nakai H, Poellinger L, Ohneda O (2015) Hypoxia-inducible factor- $3 \alpha$ promotes angiogenic activity of pulmonary endothelial cells by repressing the expression of the VE-cadherin gene. Genes Cells 20:224-241

29. Maynard MA, Evans AJ, Hosomi T, Hara S, Jewett MAS, Ohh M (2005) Human HIF-3 $\alpha 4$ is a dominant-negative regulator of HIF-1 and is down-regulated in renal cell carcinoma. FASEB J 19:1396-1406

30. Zhang P, Yao Q, Lu L, Li Y, Chen P, Duan C (2014) Hypoxiainducible factor 3 is an oxygen-dependent transcription activator and regulates a distinct transcriptional response to hypoxia. Cell Rep 6:1110-1121

31. Zhang P, Bai Y, Lu L, Li Y, Duan C (2016) An oxygen-insensitive Hif-3 $\alpha$ isoform inhibits Wnt signaling by destabilizing the nuclear $\beta$-catenin complex. eLife 5:e08996

32. Olsson L, Johansson B (2015) Ikaros and leukaemia. Br J Haematol 169:479-491

33. Kallio MA, Tuimala JT, Hupponen T, Klemelä P, Gentile M, Scheinin I, Koski M, Käki J, Korpelainen EI (2011) Chipster: user-friendly analysis software for microarray and other highthroughput data. BMC Genom 12:507

34. Paakinaho V, Kaikkonen S, Makkonen H, Benes V, Palvimo JJ (2014) SUMOylation regulates the chromatin occupancy and antiproliferative gene programs of glucocorticoid receptor. Nucleic Acids Res 42:1575-1592

35. Duan C (2016) Hypoxia-inducible factor 3 biology: complexities and emerging themes. Am J Physiol Cell Physiol 310(4):260

36. Mole DR, Blancher C, Copley RR, Pollard PJ, Gleadle JM, Ragoussis J, Ratcliffe PJ (2009) Genome-wide association of hypoxia-inducible factor (HIF)- $1 \alpha$ and HIF- $2 \alpha$ DNA binding with expression profiling of hypoxia-inducible transcripts. J Biol Chem 284:16767-16775

37. Prabhakar NR, Semenza GL (2015) Oxygen sensing and homeostasis. Physiology (Bethesda) 30:340-348

38. Drevytska T, Gonchar E, Okhai I, Lynnyk O, Mankovska I, Klionsky D, Dosenko V (2018) The protective effect of Hif3a RNA interference and HIF-prolyl hydroxylase inhibition on cardiomyocytes under anoxia-reoxygenation. Life Sci 202:131-139

39. Imeri F, Nolan KA, Bapst AM, Santambrogio S, Abreu-Rodríquez I, Spielmann P, Pfundstein S, Libertini S, Crowther L, Orlando IMC, Dahl SL, Keodara A, Kuo W, Kurtcuoglu V, Scholz CC, Qi W, Hummler E, Hoogewijs D, Wenger RH (2019) Generation of renal Epo-producing cell lines by conditional gene tagging reveals rapid HIF-2 driven Epo kinetics, cell autonomous feedback regulation, and a telocyte phenotype. Kidney Int 95(2):375-387
40. Bartoszewski R, Moszynska A, Serocki M, Cabaj A, Polten A, Ochocka R, Dell'Italia L, Bartoszewska S, Króliczewski J, Dabrowski M, Collawn JF (2019) Primary endothelial cell-specific regulation of hypoxia-inducible factor (HIF)-1 and HIF-2 and their target gene expression profiles during hypoxia. FASEB J. 33(7):7929-7941

41. Zhou X, Guo X, Chen M, Xie C, Jiang J (2018) HIF-3 $\alpha$ promotes metastatic phenotypes in pancreatic cancer by transcriptional regulation of the RhoC-ROCK1 signaling pathway. Mol Cancer Res 16:124-134

42. Krista A, Debeljak N, Kunej T (2019) Genetic variability of hypoxia-inducible factor alpha (HIFA) genes in familial erythrocytosis: analysis of the literature and genome databases. Eur J Haematol 103(4):287-299

43. Dick KJ, Nelson CP, Tsaprouni L, Sandling JK, Aïssi D, Wahl S, Meduri E, Morange P, Gagnon F, Grallert H, Waldenberger M, Peters A, Erdmann J, Hengstenberg C, Cambien F, Goodall AH, Ouwehand WH, Schunkert H, Thompson JR, Spector TD, Gieger C, Trégouët D, Deloukas P, Samani NJ (2014) DNA methylation and body-mass index: a genome-wide analysis. Lancet 383:1990-1998

44. Matsuura H, Ichiki T, Inoue E, Nomura M, Miyazaki R, Hashimoto T, Ikeda J, Takayanagi R, Fong G, Sunagawa K (2013) Prolyl hydroxylase domain protein 2 plays a critical role in diet-induced obesity and glucose intolerance. Circulation 127:2078-2087

45. Rahtu-Korpela L, Karsikas S, Hörkkö S, Blanco Sequeiros R, Lammentausta E, Mäkelä KA, Herzig K, Walkinshaw G, Kivirikko KI, Myllyharju J, Serpi R, Koivunen P (2014) HIF prolyl 4-hydroxylase-2 inhibition improves glucose and lipid metabolism and protects against obesity and metabolic dysfunction. Diabetes 63:3324-3333

46. Gray NE, Lam LN, Yang K, Zhou AY, Koliwad S, Wang J (2012) Angiopoietin-like 4 (Angptl4) protein is a physiological mediator of intracellular lipolysis in murine adipocytes. J Biol Chem 287:8444-8456

47. McQueen AE, Kanamaluru D, Yan K, Gray NE, Wu L, Li M, Chang A, Hasan A, Stifler D, Koliwad SK, Wang J (2017) The C-terminal fibrinogen-like domain of angiopoietin-like 4 stimulates adipose tissue lipolysis and promotes energy expenditure. $\mathrm{J}$ Biol Chem 292:16122-16134

48. Leonardi R, Rehg JE, Rock CO, Jackowski S (2010) Pantothenate kinase 1 is required to support the metabolic transition from the fed to the fasted state. PLoS One 5:e11107

49. Leonardi R, Rock CO, Jackowski S (2014) Pank1 deletion in leptin-deficient mice reduces hyperglycaemia and hyperinsulinaemia and modifies global metabolism without affecting insulin resistance. Diabetologia 57:1466-1475

50. Zano SP, Pate C, Frank M, Rock CO, Jackowski S (2015) Correction of a genetic deficiency in pantothenate kinase 1 using phosphopantothenate replacement therapy. Mol Genet Metab 116:281-288

51. Kersten S (2017) Angiopoietin-like 3 in lipoprotein metabolism. Nat Rev Endocrinol 13:731-739

52. Denko NC (2008) Hypoxia, HIF1 and glucose metabolism in the solid tumour. Nat Rev Cancer 8:705-713

53. Yamashita $T$, Ohneda $\mathrm{O}$, Nagano $M$, Iemitsu $M$, Makino $Y$, Tanaka H, Miyauchi T, Goto K, Ohneda K, Fujii-Kuriyama Y, Poellinger L, Yamamoto M (2008) Abnormal heart development and lung remodeling in mice lacking the hypoxia-inducible factorrelated basic helix-loop-helix PAS protein NEPAS. Mol Cell Biol 28:1285-1297

Publisher's Note Springer Nature remains neutral with regard to jurisdictional claims in published maps and institutional affiliations. 